\title{
A pyridinium-type fullerene derivative suppresses primary effusion lymphoma cell viability via the downregulation of the Wnt signaling pathway through the destabilization of $\beta$-catenin
}

\author{
AYANO KADOTA $^{1}$, MISATO MORIGUCHI ${ }^{1}$, TADASHI WATANABE ${ }^{1}$, YUICHI SEKINE ${ }^{1}$, SHIGEO NAKAMURA $^{2}$, \\ TAKUMI YASUNO $^{3}$, TOMOYUKI OHE ${ }^{3}$, TADAHIKO MASHINO ${ }^{3}$ and MASAHIRO FUJIMURO ${ }^{1}$ \\ ${ }^{1}$ Department of Cell Biology, Kyoto Pharmaceutical University, Yamashinaku, Kyoto 607-8412; \\ ${ }^{2}$ Department of Chemistry, Nippon Medical School, Musashino, Tokyo 180-0023; \\ ${ }^{3}$ Department of Pharmaceutical Sciences, Faculty of Pharmacy, Keio University, Tokyo 105-8512, Japan
}

Received August 29, 2021; Accepted November 18, 2021

DOI: $10.3892 / o r .2022 .8257$

\begin{abstract}
Primary effusion lymphoma (PEL) is defined as a rare subtype of non-Hodgkin's B cell lymphoma, which is caused by Kaposi's sarcoma-associated herpesvirus (KSHV) in immunosuppressed patients. PEL is an aggressive type of lymphoma and is frequently resistant to conventional chemotherapeutics. Therefore, the discovery of novel drug candidates for the treatment of PEL is of utmost importance. In order to discover potential novel anti-tumor compounds against PEL, the authors previously developed a pyrrolidinium-type fullerene derivative, 1,1,1',1'-tetramethyl [60]fullerenodipyrrolidinium diiodide (derivative \#1), which induced the apoptosis of PEL cells via caspase-9 activation. In the present study, the growth inhibitory effects of pyrrolidinium-type (derivatives \#1 and \#2), pyridinium-type (derivatives \#3 and \#5 to \#9) and anilinium-type fullerene derivatives
\end{abstract}

Correspondence to: Dr Masahiro Fujimuro, Department of Cell Biology, Kyoto Pharmaceutical University, Misasagi-Shichonocho 1, Yamashinaku, Kyoto 607-8412, Japan

E-mail: fuji2@mb.kyoto-phu.ac.jp

Dr Tomoyuki Ohe, Department of Pharmaceutical Sciences, Faculty of Pharmacy, Keio University, 1-5-30 Shibakoen, Minato-ku, Tokyo 105-8512, Japan

E-mail: ohe-tm@pha.keio.ac.jp

Abbreviations: AIDS, acquired immunodeficiency syndrome; ERK, extracellular signal-regulated kinase; $\mathrm{HCV}$, hepatitis $\mathrm{C}$ virus; HIV, human immunodeficiency virus; HHV-8, human

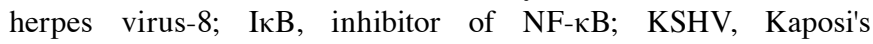
sarcoma-associated herpesvirus; LANA, latency-associated nuclear antigen; p38 MAPK, p38 mitogen-activated protein kinase; MEK, mitogen-activated protein kinase kinase; PEL, primary effusion lymphoma; RT, reverse transcriptase

Key words: $\beta$-catenin, fullerene, Kaposi's sarcoma-associated herpesvirus, primary effusion lymphoma, pyridinium fullerene, Wnt signaling (derivative \#4) against PEL cells were evaluated. This analysis revealed a pyridinium-type derivative (derivative \#5; 3-5'-(ethoxycarbonyl)-1',5'-dihydro-2' $\mathrm{H}$-[5,6]fullereno- $\mathrm{C}_{60}-\mathrm{I}_{\mathrm{h}}-[1,9-\mathrm{c}]$ pyrrol-2'-yl]-1-methylpyridinium iodide), which exhibited antitumor activity against PEL cells via the downregulation of Wnt/ $\beta$-catenin signaling. Derivative \#5 suppressed the viability of KSHV-infected PEL cells compared with KSHV-uninfected B-lymphoma cells. Furthermore, derivative \#5 induced the destabilization of $\beta$-catenin and suppressed $\beta$-catenin-TCF4 transcriptional activity in PEL cells. It is known that the constitutive activation of $\mathrm{Wnt} / \beta$-catenin signaling is essential for the growth of KSHV-infected cells. The Wnt/ $\beta$-catenin activation in KSHV-infected cells is mediated by KSHV latency-associated nuclear antigen (LANA). The data demonstrated that derivative \#5 increased $\beta$-catenin phosphorylation, which resulted in $\beta$-catenin polyubiquitination and subsequent degradation. Thus, derivative \#5 overcame LANA-mediated $\beta$-catenin stabilization. Furthermore, the administration of derivative \#5 suppressed the development of PEL cells in the ascites of SCID mice with tumor xenografts derived from PEL cells. On the whole, these findings provide evidence that the pyridinium-type fullerene derivative \#5 exhibits antitumor activity against PEL cells in vitro and in vivo. Thus, derivative \#5 may be utilized as a novel therapeutic agent for the treatment of PEL.

\section{Introduction}

Primary effusion lymphoma (PEL), also referred to as body cavity-based lymphoma, is classified as a non-Hodgkin's B cell lymphoma that develops in immunocompromised individuals, such as in patients with acquired immunodeficiency syndrome (AIDS) or those who have undergone organ transplantation and are prescribed immunosuppressants $(1,2)$. PEL cells are infected with Kaposi's sarcoma-associated herpesvirus [KSHV, also known as human herpesvirus-8 (HHV-8)] and often with Epstein-Barr virus (EBV). KSHV is the causative agent of Kaposi's sarcoma, PEL and multicentric Castleman disease (3). During a latent infection, the KSHV genome circularizes to form a double-stranded episome in the nucleus of 
PEL cells. KSHV establishes a latent infection in PEL cells and expresses several viral molecules, including viral FLIP/open reading frame (ORF)71, viral cyclin/ORF72, latency-associated nuclear antigen (LANA)/ORF73, kaposin/K12, viral interleukin-6/K2 and various microRNAs. These molecules, including several lytic phase-related molecules, dysregulate nuclear factor- $\kappa \mathrm{B}(\mathrm{NF}-\kappa \mathrm{B})$, mitogen-activated protein kinases (MAPKs), Wnt/3-catenin, AKT, p53, Jak/STAT and interferon signaling to maintain the malignant phenotype and to ensure PEL cell survival, cell cycle progression, apoptosis inhibition and immune escape $(4,5)$.

The authors previously reported that KSHV LANA-induced $\beta$-catenin stabilization, which is mediated by the interaction of LANA with glycogen synthase kinase (GSK)-3 $\beta$, leads to the activation of $\mathrm{Wnt} / \beta$-catenin signaling in infected cells (6-9). In the absence of Wnt signaling, cytoplasmic $\beta$-catenin forms a complex with Axin, adenomatous polyposis coli (APC) and GSK-3 $\beta$ in the cytoplasm. The Axin-APC complex functions as a platform for the interaction of GSK-3 $\beta$ and $\beta$-catenin, and subsequently, GSK- $3 \beta$ phosphorylates $\beta$-catenin. Phosphorylated $\beta$-catenin is conjugated with polyubiquitin and is then degraded by the $26 \mathrm{~S}$ proteasome. Although GSK-3 $\beta$ is primarily localized in the cytoplasm, a small proportion of GSK-3 $\beta$ is known to re-localize into the nucleus during the $\mathrm{S}$ phase. It was also found that LANA increased the number of cells in the S phase, and interacted with nuclear GSK-3 $\beta$, resulting in the depletion of cytoplasmic GSK-3 $\beta$. Therefore, $\beta$-catenin was stabilized in the cytoplasm of PEL and Kaposi's sarcoma cells, and the transcriptional activation of Wnt signaling target genes were stimulated in KSHV-infected cells.

The fullerene $\mathrm{C}_{60}$ (also known as buckminsterfullerene $\mathrm{C}_{60}$ ) is a unique spherical carbon molecule (10), which has been utilized as the material for bioactive substances, semiconductors and drug delivery. Since fullerene $\mathrm{C}_{60}$ is poorly soluble in $\mathrm{H}_{2} \mathrm{O}$, numerous water-soluble fullerene derivatives have been synthesized by the conjugation of various hydrophilic groups to a fullerene $\mathrm{C}_{60}$ core. The addition of these hydrophilic groups (e.g., pyrrolidinium or pyridinium moiety) confers novel biological activities to fullerene and may facilitate its use in numerous biomedical applications including in drug delivery $(11,12)$, gene delivery (13), DNA photocleaving (14), the extinction of reactive oxygen species (ROS) (15), the generation of ROS (16) and anti-bacterial activity (17). In addition, fullerene derivatives exhibit antiviral activities by inhibiting human immunodeficiency virus (HIV)-1 protease (18), HIV-1 reverse transcriptase (RT) (19), hepatitis C virus (HCV) RNA polymerase (NS5B) (19) and influenza virus endonuclease (20).

Water-soluble cationic and anionic fullerene derivatives may be utilized as novel compounds for the treatment of PEL. The authors previously developed a pyrrolidinium-type fullerene derivative $\left(1,1,1^{\prime}, 1^{\prime}\right.$-tetramethyl [60]fullerenodipyrrolidinium diiodide) and found that this derivative induced the generation of ROS and inhibited viral enzymes $(16,19,20)$ (referred to as derivative \#1 in Fig. 1). It was also found that this pyrrolidinium-type fullerene exerts antitumor effects against PEL (21). In addition, in PEL cells, this pyrrolidinium-type fullerene (derivative \#1) reduced the phosphorylation of AKT at Ser473 and inhibited the phosphorylation of procaspase-9 at Ser196. Ser473-phosphorylated AKT (i.e., activated AKT) is known to phosphorylate procaspase-9 at Ser196, which inactivates procaspase-9 (22). Thus, derivative \#1 induces the apoptosis of PEL cells via caspase-9 activation and AKT inactivation. Since derivative \#1 has a cation-functionalized moiety (pyrrolidinium) and has several beneficial biological properties, other cationic fullerene derivatives were synthesized (Fig. 1) (16,17,19,21,23-25). In the present study, the inhibitory activities of these derivatives on PEL cell growth were analyzed and the underlying molecular mechanism(s) leading to PEL cell growth inhibition were evaluated.

\section{Materials and methods}

Agents, cell lines and cell culture. Fullerene derivatives \#1, \#2 (16,19,21), \#3 (23), \#5 (24,25), \#7 (24), \#8 (25) and \#9 (25) were synthesized and purified according to previously reported methods. Derivative \#4 was synthesized via 1,3-dipolar cycloaddition reactions of azomethine ylide generated from 4-dimetylaminobenzaldehyde and 4-pycolylamine, followed by methylation with methyl iodide. Derivative \#6 was prepared by butylation of the precursor used for the synthesis of derivative \#5, with butyl iodide instead of methyl iodide. All the fullerene derivatives were dissolved in DMSO at a concentration of $10 \mathrm{mM}$ and were used as stock solutions. KSHV-positive PEL cell lines (BCBL1, BC2, BC3, HBL6 and JSC1) and KSHV-negative lymphoma cell lines (Ramos, Raji and DG75) were kindly provided by Dr S.D. Hayward (Johns Hopkins University School of Medicine, Baltimore, MD, USA) (6) and were cultured in RPMI-1640 medium with $10 \%$ fetal bovine serum (FBS). The Ramos, Raji, and DG75 are classified into Burkitt's lymphoma, and Raji cells are EBV-positive. The HeLa cell line (RCB0007) was provided by the RIKEN BioResource Research Center. Peripheral blood mononuclear cells (PBMCs; cat. no. 1007, Astarte Biologics, LLC; https://cellero.com/products/pbmc/) were cultured in RPMI-1640 medium with 20\% FBS.

Cell proliferation assay. PEL cells, KSHV-negative B-lymphoma cells and PBMCs $\left(1 \times 10^{4}\right.$ cells/well) were seeded in a 96-well plate and cultured in medium with or without each compound at $37^{\circ} \mathrm{C}$ for $24 \mathrm{~h}$. The viable cell number was determined using Cell Count Reagent SF (Nacalai Tesque, Inc.) as previously described (26). The SF reagent (10 $\mu$ l) was mixed with $90 \mu \mathrm{l}$ cell-medium suspension in a well, and the mixture was incubated at $37^{\circ} \mathrm{C}$ for $2 \mathrm{~h}$. The optical density of each sample was measured at $450 \mathrm{~nm}$ on a microplate spectrophotometer (Tecan M200; Tecan Group, Ltd.) and is expressed as a percentage (the absorbance of untreated cells was defined as $100 \%)$. The $50 \%$ cytotoxic concentration $\left(\mathrm{CC}_{50}\right)$ is defined as the concentration of compound that reduces cell viability by $50 \%$. The $\mathrm{CC}_{50}$ value of each fullerene derivative was calculated using non-linear regression using GraphPad Prism 7 (GraphPad Software, Inc.).

Western blot analysis and antibodies. Western blot analysis was performed as previously described (26). For sample preparation, the cells $\left(3 \times 10^{6}\right)$ were solubilized in $300 \mu$ l SDS sample buffer (containing 1\% 2-mercaptoethanol, $0.2 \mathrm{mM} \mathrm{NaF}, 1 \mathrm{mM}$ $\beta$-glycerophosphate, $1 \mu \mathrm{g} / \mathrm{ml}$ aprotinin and $0.25 \mathrm{mM}$ PMSF), boiled for $5 \mathrm{~min}$, and sonicated for $15 \mathrm{sec}$ with a probe type sonicator for chromosomal DNA disruption. The protein 
concentration of the sample was determined using a Protein Assay BCA kit (Nacalai Tesque, Inc.) or by the measurement of the absorbance at $280 \mathrm{~nm}$ on a microplate spectrophotometer (Tecan M200). The resulting lysate (15 or $20 \mu \mathrm{g}$ ) was applied to SDS-PAGE on 8,10 or $12 \%$ polyacrylamide gel followed by western blotting. Proteins were transferred onto a ClearTrans nitrocellulose membrane (FUJIFILM Wako) and the membrane was incubated with blocking buffer, $3 \%$ non-fat dry milk and $0.1 \%$ Tween-20 in PBS, for $1 \mathrm{~h}$ at room temperature. The membrane was incubated with primary antibodies (1,000-fold dilution) diluted with Can Get Signal Immunoreaction Enhancer Solution (Toyobo Life Science) at $4^{\circ} \mathrm{C}$ overnight (or at room temperature for $2 \mathrm{~h}$ ) and subsequently with a secondary antibody, HRP-conjugated anti-mouse (NA931V) or anti-rabbit IgG antibody (NA934V) (Cytiva) (2,000- or 4,000-fold dilution) at room temperature for $1 \mathrm{~h}$. The membrane was then mixed with ECL Western Blotting Detection Reagents (Cytiva) and visualized with $\mathrm{X}$-ray film. In the densitometric analysis of western blotting, the band intensities of the detected proteins were measured using ImageJ software version 1.52a (National Instituters of Health). The band intensities of the detected protein (or the phosphorylated protein) were normalized to those of GAPDH (or the unphosphorylated protein). The normalized values are presented at the bottom of the blots.

The following antibodies were used for western blotting, immunofluorescence assay (IFA) and co-immunoprecipitation (co-IP): Anti-Thr202/Tyr204-phospho-ERK1/2 (cat. no. 4370), caspase-3 (cat. no. 9662), Ser9-phospho-GSK-3ß (cat. no. 5558), Ser33/37/Thr41-phospho- $\beta$-catenin (cat. no. 9561), Ser473-phospho-AKT (cat. no. 4060), Tyr705-phospho-STAT3 (cat. no. 9145), Akt (cat. no. 9272) (all from Cell Signaling Technology, Inc.); anti-Thr180/Tyr182-phospho-p38 MAPK (cat. no. 612281), p38 MAPK (cat. no. 612168), panERK (cat. no. 610123), GSK-3 $\beta$ (cat. no. 610202), $\beta$-catenin

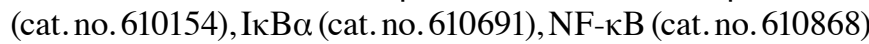
(all from BD Biosciences); anti-Axin (cat. no. sc-293190), $\beta$-actin (cat. no. sc-69879), cyclin D1 (cat. no. sc-718) (all from Santa Cruz Biotechnology, Inc.); anti-Flag (DDDDK)-tag (cat. no. 185-3L), HA-tag (cat. no. M180-3) and glyceraldehyde-3-phosphate dehydrogenase (GAPDH) (cat. no. M171-3) (all from MBL International Co.). FK2 antibodies that were previously established (27) were used to detect polyubiquitin conjugates. The anti-LANA rabbit polyclonal antibody, which recognizes the $\mathrm{N}$-terminal region (amino acids 1-275) of LANA, was also established in the authors' laboratory. As the present study had a research resource limitation, several western blotting (as indicated in the specific figure legends) experiments were performed twice using independent samples.

Caspase assay. The cells $\left(4 \times 10^{5}\right.$ cells $\left./ \mathrm{ml}\right)$ were incubated with $20 \mu \mathrm{M}$ of derivative \#5 for $8 \mathrm{~h}$, and caspase-3/7 activities were measured using the Caspase-Glo Assay with a luciferin-conjugated polypeptide substrate (Promega Corporation). In accordance with a previous study by the authors, the activation of caspases in PEL cells was detected at 6-12 $\mathrm{h}$ following the addition of anticancer drugs (26), and the drug-treatment time was set at $8 \mathrm{~h}$. The luminescence was measured on a Tecan M200 luminescence microplate reader (Tecan Group, Ltd.). The caspase activities of the untreated cells were defined as 1.0.
Lactate dehydrogenase $(L D H)$ assay. The cells $\left(1 \times 10^{4}\right.$ cells/well) were seeded in a 96-well plate and cultured in medium with 20 or $50 \mu \mathrm{M}$ derivative \#5 for $24 \mathrm{~h}$. The dead cell-derived LDH in the culture supernatants was measured using the Cytotoxicity LDH Assay kit (Nacalai Tesque, Inc.). The optical density of each sample was measured at $490 \mathrm{~nm}$ using a microplate spectrophotometer (Tecan M200; Tecan Group, Ltd.) and is expressed as a percentage. The absorbance of cells treated with a detergent solution (positive control) that is contained in the LDH Assay kit was defined as $100 \%$.

Flow cytometry. To analyze the cell cycle, the DNA amount was measured using flow cytometry. Cells were fixed in ethanol for $1 \mathrm{~h}$ at $-20^{\circ} \mathrm{C}$ and the fixed cells were then incubated with $20 \mu \mathrm{g} / \mathrm{ml}$ propidium iodide (Nacalai Tesque, Inc.) and 1,000 $\mu \mathrm{g} / \mathrm{ml} \mathrm{RNaseA}$ (Takara Bio Inc.) in PBS for $10 \mathrm{~min}$ at $37^{\circ} \mathrm{C}$. The cells washed with PBS were subjected to analysis using a LSRFortessa Flow Cytometer(BD Biosciences). Dead cells were excluded by gating on forward scatter and side scatter profiles.

Luciferase reporter assay. Wnt/ $\beta$-catenin-dependent transcriptional activity was evaluated with the luciferase reporter assay using GL3-OT as previously described $(6,7)$. The BC3 PEL cells $\left(4 \times 10^{5}\right)$ were transfected with $0.4 \mu \mathrm{g}$ GL3-OT (TCF4 reporter plasmid) and $0.1 \mu \mathrm{g}$ of $\mathrm{pSV}-\beta$-Gal plasmid (Promega Corporation) using ScreenFect A plus (FUJIFILM Wako Pure Chemical Corporation) according to the manufacturer's instructions. GL3-OT was kindly provided by Dr K. Kinzler and Dr B. Vogelstein (Johns Hopkins University School of Medicine, Baltimore, MD, USA). The transfected cells were incubated for $24 \mathrm{~h}$ at $37^{\circ} \mathrm{C}$ in medium containing $20 \mu \mathrm{M}$ of derivative \#5. The cells were lysed by resuspension with $0.1 \mathrm{ml}$ lysis buffer A [50 mM Tris- $\mathrm{HCl}$ (pH 7.8), 0.05\% Nonidet P-40 (NP-40) and $1 \mathrm{mM}$ DTT] and twice freeze-thaw treatment. Cell lysates were subjected to the Firefly luciferase and $\beta$-gal assays, as previously described $(6,26)$. The luciferase activity was measured using a GloMax 20/20 luminometer (Promega Corporation). The Firefly luciferase activity was normalized to $\beta$-gal activity. The value of luciferase activity/ $\beta$-gal activity of DMSO-treated cells was defined as 1.0.

Cycloheximide $(\mathrm{CHX})$ chase analysis. The cells $\left(5 \times 10^{5}\right.$ cells/well) were seeded in a 6 -well plate and cultured in medium with $20 \mu \mathrm{M}$ derivative \#5 or DMSO in the presence of $50 \mu \mathrm{g} / \mathrm{ml}$ CHX (Nacalai Tesque, Inc.) for 0, 2, 4 and $6 \mathrm{~h}$. Harvested cells were solubilized in $100 \mu \mathrm{l}$ SDS sample buffer and subjected to western blot analysis using anti- $\beta$-catenin antibody.

Reverse transcription-quantitative polymerase chain reaction $(R T-q P C R)$. Total RNA was extracted and purified from $1 \times 10^{6}$ cells using RNAiso Plus (Takara Bio Inc.). First-strand cDNA was synthesized for $15 \mathrm{~min}$ at $37^{\circ} \mathrm{C}$ from $80 \mathrm{ng}$ total RNA using the ReverTra Ace qPCR RT kit (cat. no. FSQ-101; Toyobo Life Science). Real-time PCR was performed with the THUNDERBIRD SYBR qPCR Mix (cat. no. QPS-201; Toyobo Life Science) using the primer sets listed in Table I. The program of PCR was as follows: $95^{\circ} \mathrm{C} 3 \mathrm{~min}$ (pre-denaturation); followed by 40 cycles of $95^{\circ} \mathrm{C}$ for $10 \mathrm{sec}$ (denaturation), $55^{\circ} \mathrm{C}$ for $30 \mathrm{sec}$ (annealing and extension). The results were normalized to GAPDH using the $2^{-\Delta \Delta \mathrm{Cq}}$ method (28). 
Table I. Primers used for reverse transcription-quantitative PCR.

\begin{tabular}{lll}
\hline Gene & \multicolumn{1}{c}{ Forward sequence } & \multicolumn{1}{c}{ Reverse sequence } \\
\hline$\beta$-catenin & 5'-TTGATGGGCTGCCAGATCTG-3' & 5'-CTTTCTGAGATACCAGCCCAC-3' \\
vIL-6 & 5'-GGTCGGTTCACTGCTGGTATC-3' & 5'-ATGCCGGTACGGTAACAGAG-3' \\
GAPDH & 5'-TGACCACAGTCCATGCCATC-3' & 5'-GGGGAGATTCAGTGTGGTGG-3' \\
LANA & 5'-TCCCGCAACACCTTTA-3' & 5'-CGGAGACACAGGATGG-3' \\
k-bZip & 5'-AAGTCTCTTGGACAAG-3' & 5'-TGAGCATGGCAGATGT -3' \\
RTA & 5'-ATAATCCGAATGCACACATCTTCCACCAC-3' & 5'-TCGTCGGCCTCTCGGACGAAACTGA-3'
\end{tabular}

vIL-6, viral interleukin-6; GAPDH, glyceraldehyde-3-phosphate dehydrogenase; LANA, latency associated nuclear antigen; RTA, replication transcription activator.

Co-IP assay. In the co-IP experiments with overexpressed LANA and GSK-3 $\beta$, HeLa cells $\left(1 \times 10^{6}\right.$ cells) were transfected with $2.5 \mu \mathrm{g}$ Flag-LANA (dR) (6) and $2.5 \mu \mathrm{g}$ of HA-GSK-3 $\beta$ (6) plasmids for $15 \mathrm{~h}$ at $35^{\circ} \mathrm{C}$ using the calcium-phosphate method described in the study by Chen and Okayama (29). The transfection medium was changed to fresh normal medium, and the cells were cultured for $24 \mathrm{~h}$ at $37^{\circ} \mathrm{C}$. Subsequently, the cells were treated with $20 \mu \mathrm{M}$ of derivative \#5 for $10 \mathrm{~h}$. Cell extracts were prepared with $0.8 \mathrm{ml}$ of lysis buffer B [50 mM Tris- $\mathrm{HCl}$ (pH 7.8), $50 \mathrm{mM} \mathrm{NaCl}, 1 \%$ glycerol, $1 \mathrm{mM}$ DTT and $0.05 \% \mathrm{NP}-40]$. In order to immunoprecipitate HA-GSK-3 $\beta$, the extracts $(0.8 \mathrm{ml})$ were incubated for $1 \mathrm{~h}$ at $4^{\circ} \mathrm{C}$ with $20 \mu \mathrm{l}$ (bead volume) protein G Sepharose beads (Merck KGaA) immobilized with $1 \mu \mathrm{g}$ anti-HA antibody. The beads were washed three times with lysis buffer B and resuspended in $40 \mu \mathrm{l}$ SDS sample buffer with 6\% 2-ME. The suspension was boiled for $5 \mathrm{~min}$ and centrifuged at $11,000 \mathrm{x} \mathrm{g} \mathrm{(12,000} \mathrm{rpm)} \mathrm{for}$ $0.5 \mathrm{~min}$ to precipitate the beads. The supernatant was collected by the small-bore gel loading tip (cat. no. 010-Q; Thermo Fisher Scientific, Inc.). In order to detect the interaction of Flag-LANA and HA-GSK-3 $\beta, 20 \mu$ l supernatant was subjected to SDS-PAGE on $8 \%$ polyacrylamide gel followed by western blot analysis with anti-Flag antibody, as described above.

In the co-IP assay for endogenous $\beta$-catenin, BC3 PEL cells ( $1 \times 10^{7}$ cells) were cultured in medium with $20 \mu \mathrm{M}$ of derivative \#5 and $10 \mu \mathrm{M}$ of MG132 for 2 or $4 \mathrm{~h}$. The harvested cells were lysed with $0.8 \mathrm{ml}$ of RIPA buffer [50 mM Tris- $\mathrm{HCl}(\mathrm{pH} 7.8)$, $0.1 \%$ SDS, $0.5 \%$ sodium deoxycholate, $1 \%$ NP-40, $150 \mathrm{mM}$ $\mathrm{NaCl}, 1 \mathrm{mM}$ NEM and $1 \mathrm{mM}$ DTT]. In order to immunoprecipitate endogenous $\beta$-catenin, the cell lysates were incubated for $1 \mathrm{~h}$ at $4^{\circ} \mathrm{C}$ with $20 \mu \mathrm{l}$ protein G Sepharose beads (Merck $\mathrm{KGaA})$ immobilized with $1 \mu \mathrm{g}$ anti- $\beta$-catenin antibody. The procedures for preparation of the immunoprecipitates and SDS-PAGE were the same as those described above. In order to detect the polyubiquitin-conjugated $\beta$-catenin, the immunoprecipitates were probed by western blot analysis with FK2 antibody, as previously described (27).

Measurement of proteasome activity. The proteasome activity was measured as previously described (26). Briefly, cells $\left(1 \times 10^{6}\right)$ were lysed in $0.2 \mathrm{ml}$ buffer containing $50 \mathrm{mM}$ Tris- $\mathrm{HCl}$ (pH 7.6), 1 mM MgCl $2,0.1$ mM EDTA, $1 \%$ glycerol, 1 mMDTT, $0.2 \mathrm{mM}$ ATP and $0.2 \%$ NP-40, and cells were homogenized with $27 \mathrm{G}$ needles. The lysate protein concentrations were measured using the BCA method using a Protein Assay Bicinchoninate kit (Nacalai Tesque, Inc.). The proteasome activity in the cell lysates were assessed with the fluorogenic peptide, Suc-Leu-Leu-Val-Tyr-4-methylcoumaryl7-amide (MCA) (Peptide Institute, Inc.). The AMC fluorescence intensity (excitation, $380 \mathrm{~nm}$; emission, $460 \mathrm{~nm}$ ) was determined using a Tecan M200 microplate spectrofluorometer (Tecan Group, Ltd.).

Animal experiments. Animal experiments were approved (approval no. 18-039) by the Animal Experimentation Committee of Kyoto Pharmaceutical University (Kyoto, Japan) and conducted in accordance with the Guidelines for the Care and Use of Laboratory Animals of the Science Council of Japan. To establish a PEL-xenograft mouse model, BCBL1 cells as a transplant tumor cell and SCID mice as recipient mice were used $(26,30,31)$. C.B-17 IcrHsd-Prkcd SCID male mice aged 5 weeks were purchased from SHIMIZU Laboratory Supplies Co., Ltd. The mice were kept under standard laboratory conditions (temperature $22 \pm 2^{\circ} \mathrm{C}$; relative humidity $50 \pm 10 \%$; 12-h light/dark cycle) with access to food and water ad libitum. BCBL1 cells were injected intraperitoneally into the SCID mice twice (body weight, 20-24 g). A BCBL1 cell suspension with $1 \mathrm{ml}$ PBS $\left(4.5 \times 10^{7}\right.$ cells/mouse) was injected at 10 days, and a BCBL1 cell suspension $\left(3.8 \times 10^{7}\right.$ cells/mouse) was additionally injected at 1 day prior to the commencement of fullerene derivative administration. Derivative \#5 (or DMSO) dissolved in corn oil was administered into the intraperitoneal region at a dose of $20 \mathrm{mg} / \mathrm{kg}$ body weight every 2 days for the first 1 week and subsequently every 3 days for following 2 weeks. The DMSO-administered normal mice $(\mathrm{n}=3)$, derivative $\# 5$-administered normal mice $(n=3)$, DMSO-administered PEL-xenografted mice $(n=3)$, and derivative $\# 5$-administered PEL-xenografted mice $(n=3)$ were observed, and their body weight was measured each day for 3 weeks. All mice were euthanized on day 21, and their ascites and organs were collected. The ascites collected from each mouse was centrifuged at $300 \times \mathrm{g}(1,400 \mathrm{rpm})$ for $5 \mathrm{~min}$, and tumor cells were precipitated to determine the weight volume of the tumor cells. All mice that reached the study endpoint were euthanized by cervical dislocation under $2-3 \%$ isoflurane anesthesia. The humane endpoints were determined 
$\# 1$
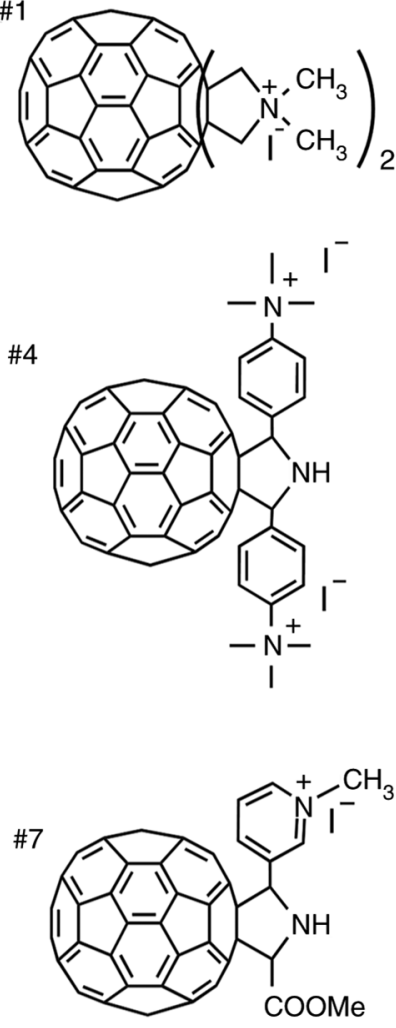

\#2

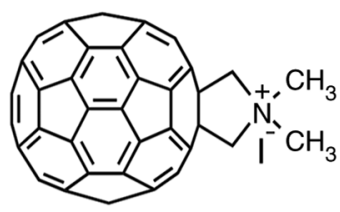

\#5

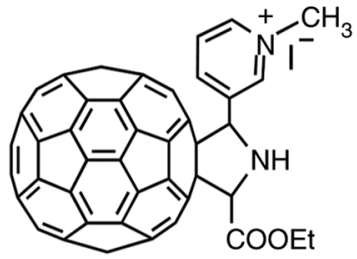

\#8

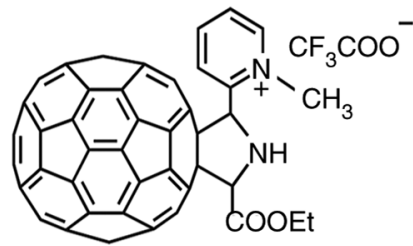

\#3

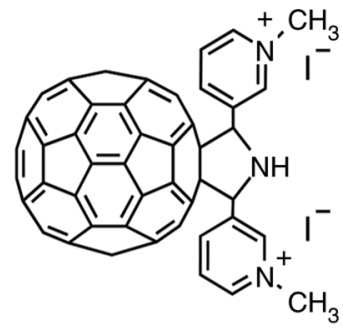

\#6

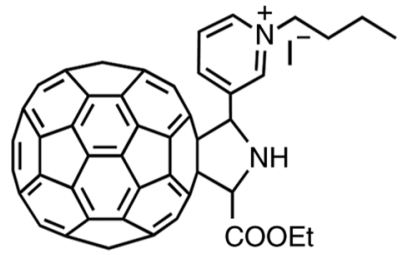

Figure 1. Fullerene derivatives. The structures of the fullerene derivatives evaluated in the present study are presented. These fullerene derivatives can be classified into pyrrolidinium-type (derivatives \#1 and \#2), pyridinium-type (derivatives \#3 and \#5-\#9) and anilinium-type (derivative \#4).

to be when the xenograft tumor diameter was $>20 \mathrm{~mm}$, the xenograft tumor reached $>20 \%$ of the animal body weight, body weight loss $>20 \%$ occurred due to tumor growth, and signs of immobility, the inability to eat, ulceration, infection, or necrosis were observed. Death was verified by observation of pupil dilation as well as ceasing of breath and heartbeat.

IFA and phase-contrast image. In the IFA to detect the localization of LANA and GSK- $3 \beta$, HeLa cells $\left(2 \times 10^{5}\right.$ cells) grown on a glass slide were transfected with $3 \mu \mathrm{g}$ Flag-LANA (dR) and $2 \mu \mathrm{g} \mathrm{HA}-\mathrm{GSK}-3 \beta$ plasmids for $15 \mathrm{~h}$ at $35^{\circ} \mathrm{C}$ according to the method described in the study by Chen and Okayama (29). The transfection medium was changed, and cells were cultured in normal medium for $24 \mathrm{~h}$ at $37^{\circ} \mathrm{C}$. Subsequently, the cells were treated with $20 \mu \mathrm{M}$ of derivative $\# 5$ for $10 \mathrm{~h}$ and were fixed with $4 \%$ paraformaldehyde for $15 \mathrm{~min}$ at $4{ }^{\circ} \mathrm{C}$ and permeabilized with $0.1 \%$ Triton $\mathrm{X}-100$ in PBS for $10 \mathrm{~min}$ at room temperature. In the animal experiment, ascites and BCBL1 cells were fixed on a glass slide with $4 \%$ paraformaldehyde at room temperature for $1 \mathrm{~h}$ and permeabilized with $0.1 \%$ Triton X-100 in PBS. The cells were then incubated in PBS-T containing 10\% FBS and the primary antibody (anti-HA, anti-Flag or anti-LANA antibody) (500-fold dilution) at room temperature for $1 \mathrm{~h}$. The cells were further treated with the secondary antibody, Alexa Fluor 488-labeled donkey anti-mouse (cat. no. A32766), Alexa Fluor 594-labeled donkey anti-rabbit (cat. no. A32754), or Alexa Fluor 488-labeled donkey anti-rabbit IgG antibody (cat. no. A32790) (Thermo Fisher Scientific, Inc.) (3,000-fold dilution) at room temperature for $1 \mathrm{~h}$. The stained samples were embedded in Fluoro-KEEPER Antifade Reagent, Non-Hardening Type with DAPI (12745-74) (Nacalai Tesque, Inc.) and were observed under a confocal LSM 800 microscope (Carl Zeiss AG) using LSM software ZEN 3.3 lite/blue edition (Carl Zeiss AG).

Phase-contrast images were obtained using an inverted Olympus IX-71 microscope (Olympus Corporation). Cells seeded in a $6-\mathrm{cm}$ dish were cultured in media, and the phase-contrast images of living cells were obtained under an inverted microscope with the 10X objective using analysis software DP2-BSW (Olympus Corporation).

Statistical analysis. Statistical analysis was performed using GraphPad Prism 7 (GraphPad Software, Inc.). Data are presented as the mean $\pm \mathrm{SD}$, and the standard deviation was determined by analyzing the data from at least three experiments. Statistical differences between groups were determined using one-way analysis of variance (ANOVA) followed by Dunnett's test for multiple comparisons or the two-tailed Student's t-test. A value of $\mathrm{P}<0.05$ was considered to indicate a statistically significant difference.

\section{Results}

Effects of eight fullerene derivatives on PEL cell viability. First of all, the effects of two pyrrolidinium-type (derivatives \#1 and \#2), six pyridinium-type (derivatives \#3 and \#5 to \#9), and one anilinium-type (derivative \#4) fullerene derivatives on PEL cell viability were analyzed (Fig. 2A-I). 
Table II. Cytotoxic effects of fullerene derivative \#5 on B-lymphoma cell lines.

\begin{tabular}{|c|c|c|c|c|c|c|c|c|}
\hline \multirow[b]{3}{*}{ Derivative } & \multicolumn{8}{|c|}{$\mathrm{CC}_{50}{ }^{\mathrm{a}}(\mu \mathrm{M})^{\mathrm{b}}$} \\
\hline & \multicolumn{3}{|c|}{ KSHV (-) cell lines } & \multicolumn{5}{|c|}{ KSHV (+) cell lines } \\
\hline & DG75 & Ramos & Raji & HBL6 & BCBL1 & $\mathrm{BC} 3$ & $\mathrm{BC} 2$ & JSC1 \\
\hline$\# 1$ & 23.4 & 24.9 & $\mathrm{DN}$ & 19.7 & $>25$ & 15.5 & $\mathrm{DN}$ & $\mathrm{DN}$ \\
\hline$\# 2$ & 16.9 & 17.8 & $\mathrm{DN}$ & 19.7 & 23.2 & 13.0 & $\mathrm{DN}$ & $\mathrm{DN}$ \\
\hline \#3 & 17.2 & 17.7 & $\mathrm{DN}$ & 15.5 & 17.2 & 18.9 & $\mathrm{DN}$ & $\mathrm{DN}$ \\
\hline$\# 4$ & 18.3 & 18.8 & $\mathrm{DN}$ & 19.0 & 18.1 & 20.6 & $\mathrm{DN}$ & $\mathrm{DN}$ \\
\hline$\# 5^{\mathrm{c}}$ & $>50$ & 36.9 & $>50$ & 10.5 & 10.9 & 9.6 & 5.9 & 16.7 \\
\hline \#6 & $>25$ & $>25$ & $\mathrm{DN}$ & 16.6 & 17.8 & 9.6 & $\mathrm{DN}$ & $\mathrm{DN}$ \\
\hline$\# 7$ & 18.8 & $>25$ & $\mathrm{DN}$ & 18.1 & 15.8 & 9.7 & $\mathrm{DN}$ & $\mathrm{DN}$ \\
\hline$\# 8$ & $>25$ & $>25$ & $\mathrm{DN}$ & $>25$ & $>25$ & $>25$ & $\mathrm{DN}$ & DN \\
\hline$\# 9$ & $>25$ & $>25$ & $\mathrm{DN}$ & $>25$ & $>25$ & 19.3 & $\mathrm{DN}$ & DN \\
\hline
\end{tabular}

${ }^{\mathrm{a}} \mathrm{CC}_{50}$, cytotoxic concentration of fullerene derivatives that reduces cell viability by $50 \%$. ${ }^{\mathrm{b}} \mathrm{The} \mathrm{CC}_{50}$ values of \#1, 2, 3, 4, 6, 7, 8 and 9 were calculated using the data shown in Fig. 2A-I, respectively. ${ }^{\circ}$ The $\mathrm{CC}_{50}$ values of $\# 5$ was calculated using the data shown in Fig. 2J (and in Fig. 2E for the HBL6 cells).

KSHV-infected PEL cell lines (HBL6, BCBL1 and BC3) and KSHV-uninfected B-lymphoma cell lines (DG75 and Ramos) were cultured in medium with or without the fullerene derivative. After $24 \mathrm{~h}$, the number of viable cells was quantified. The tested derivatives presented various viability profiles against each B-lymphoma cell line. Derivative \#1 increased the viability of the DG75 and Ramos cells at the concentrations of 6.25 and $12.5 \mu \mathrm{M}$ compared with the controls, and derivatives \#3 and \#4 increased the viability of the BC3 PEL cells at the concentrations of $6.25 \mu \mathrm{M}$. Although the viability of the KSHV-uninfected DG75 and Ramos cells decreased by $0-15 \%$ at the high concentration $(25 \mu \mathrm{M})$ of derivatives $\# 8$ and \#9, the uninfected cells were less sensitive to $25 \mu \mathrm{M}$ of these derivatives compared with the PEL cells. On the other hand, derivatives \#3 and \#4 decreased the viability of all cell lines at $25 \mu \mathrm{M}$. The PEL cell lines exhibited sensitivity to derivatives \#5 and \#6, whereas the KSHV-negative cells were less sensitive to these derivatives (Fig. 2A-I). In particular, derivative \#5 (3-[5'-(ethoxycarbonyl)-1',5'-dihydro-2'H-[5,6] fullereno- $\mathrm{C}_{60}-\mathrm{I}_{\mathrm{h}}$-[1,9-c]pyrrol-2'-yl]-1-methylpyridinium iodide) markedly inhibited the proliferation of PEL cell lines compared with KSHV-uninfected B-cell lines. To assess the accurate $\mathrm{CC}_{50}$ of derivative $\# 5$ and the specificity for PEL, the cytotoxic effects of derivative \#5 on various B-cell lines were analyzed (Table II). The results revealed that derivative \#5 reduced the number of viable PEL cells (BCBL1, BC3, $\mathrm{BC} 2$ and JSC1) compared with the uninfected cells (DG75, Ramos and Raji) (Fig. 2J). Indeed, derivative \#5 was the most potent inhibitor of PEL cell viability. The cytotoxic effects of derivatives \#1 to \#9 on B-lymphoma cells are summarized in Table II. Derivative \#5 was active against PEL cell lines $\left(\mathrm{CC}_{50}\right.$, 6-17 $\mu \mathrm{M}$ ), while the KSHV-uninfected $\mathrm{B}$ cell lines were insensitive to derivative $\# 5\left(\mathrm{CC}_{50},>35 \mu \mathrm{M}\right)$. Moreover, the cytotoxic effects of derivative $\# 5$ on human PBMCs were evaluated. Although $5 \mu \mathrm{M}$ derivative \#5 decreased the viability of the PBMCs by $6.4 \%$, marked toxicity was not detected in $<25 \mu \mathrm{M}$ derivative \#5-treated PBMCs (Fig. 2K). Since derivative \#5 was the most potent inhibitor of PEL cell viability, the underlying molecular mechanism(s) contributing to this inhibition were analyzed.

Derivative \#5 induces the suppression of PEL cell growth and induces the formation of cell clumps. The present study then examined whether the cytotoxic effects of derivative \#5 on PEL cells were due to apoptosis. KSHV-infected PEL cell lines (BC2, JSC1, BC3 and BCBL1) and KSHV-uninfected B-lymphoma cell lines (DG75 and Raji) were treated with $20 \mu \mathrm{M}$ of derivative \#5 for $8-24 \mathrm{~h}$ and cell extracts from harvested cells were examined by western blot analysis. An increase in cleaved (i.e., activated) caspase-3 was not detected in the PEL cell lines (BC2, JSC1, BC3 and BCBL1) treated with $20 \mu \mathrm{M}$ of derivative \#5 (Fig. 3A). Moreover, the activation of caspase-3/7 activities were monitored in the Raji, BC2, BC3 and BCBL1 cells treated with derivative \#5 using a colorimetric assay (Fig. 3B). However, no increase in caspase-3/7 peptidase activities was detected in the cells treated with derivative \#5. In order to further explore the mechanisms through which derivative \#5 decreases PEL cell viability, the number of dead cells were measured following treatment with derivative \#5 using an LDH assay and flow cytometry (Fig. 3D and E). LDH assay revealed that treatment with $50 \mu \mathrm{M}$ derivative \#5 increased the number of dead BCBL1 and BC 3 cells by $\sim 7-15 \%$, although significant differences were not detected with $20 \mu \mathrm{M}$ of the derivative \#5 (Fig. 3C). To analyze the cell cycle and the sub-G1 phase including dead cells, the DNA amount of PEL cells (BC3 and BCBL1) treated with derivative \#5 was measured using flow cytometry (Fig. 3D and E). As was expected, derivative \#5 increased the number of cells at the sub-G1 phase in a concentration-dependent manner. These data indicated that derivative \#5 induced caspase-independent cell death and decreased PEL cell viability. 

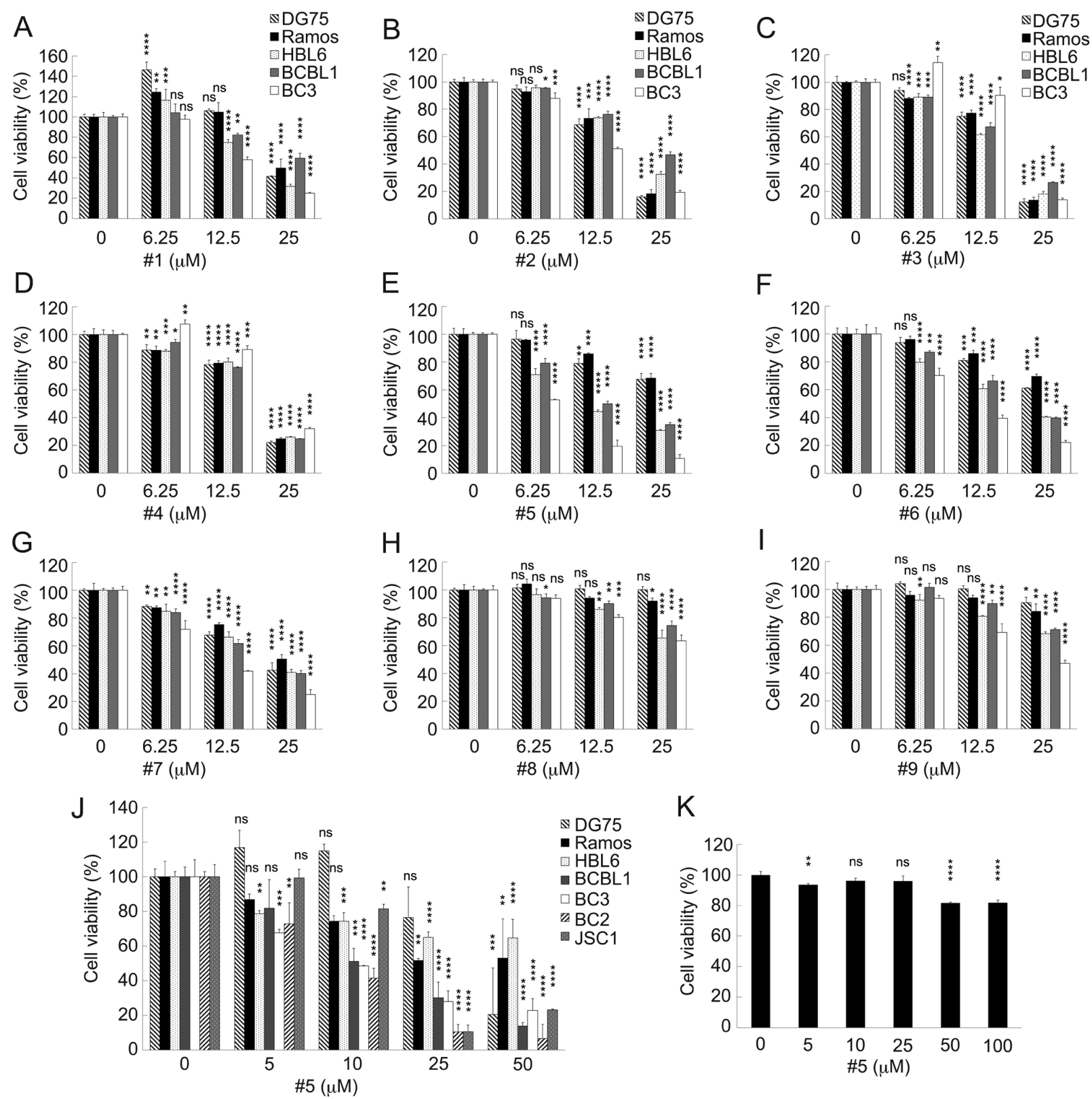

$\mathrm{K}$

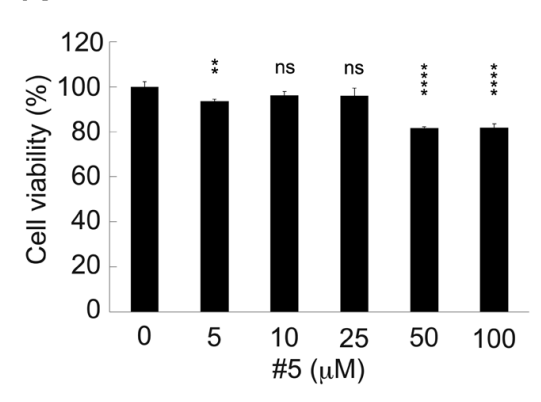

Figure 2. Effects of the fullerene derivatives on the viability of KSHV-positive PEL cells and KSHV-negative B cell lines. (A-I) Effects of the fullerene derivatives on the viability of KSHV-positive PEL cells and KSHV-negative B cell lines. KSHV-positive PEL cells (BCBL1, BC3 and HBL6) and KSHV-negative cells (Ramos and DG75) were incubated with the indicated concentrations of the fullerene derivatives for $24 \mathrm{~h}$ and the number of viable cells was assessed. The cell viability of the respective untreated cells was defined as 100\%. (J) The effects of derivative \#5 on the viability of KSHV-positive PEL cells (BCBL1, BC2, BC3 and JSC1) and KSHV-negative B cells (Ramos, DG75 and Raji). Cells were incubated with derivative \#5 for 24 h. The viability of the respective untreated cells was defined as 100\%. (K) Effects of derivative \#5 on human PBMCs. The human PBMCs were treated with various concentrations of derivative $\# 5$ for $24 \mathrm{~h}$ and the number of viable cells was measured. The cell viability of the untreated cells was defined as $100 \%$. (A-K) Data are based on three independent experiments. The results are presented as the mean \pm SD. KSHV, Kaposi's sarcoma-associated herpesvirus; PEL, primary effusion lymphoma; PBMCs, peripheral blood mononuclear cells. ${ }^{*} \mathrm{P}<0.05,{ }^{* *} \mathrm{P}<0.005,{ }^{* * * *} \mathrm{P}<0.0005$ and ${ }^{* * * * *} \mathrm{P}<0.00005$, statistically significant difference compared with the control group (or DMSO-treated group). ns, not significant.

Subsequently, the effects of derivatives \#5, \#3 and \#8 on the morphology of BCBL1 and BC3 PEL cells were examined (Fig. 3F). The morphology of the BC2 PEL cells and KSHV-uninfected Ramos cells is illustrated in Fig. S1. Derivatives \#5, \#3 and \#8 led to the formation of cell clumps in all tested cells; of note, derivative \#5 prominently induced cell-to-cell clumping (Figs. 3F and S1). Among the tested derivatives, derivative \#5 induced the largest cell clumps, suggesting the association between cell clumping formation and cell death by derivative \#5.
Derivative \#5 suppresses Wnt/ $\beta$-catenin signaling in PEL cells through the destabilization of $\beta$-catenin. NF- $\mathrm{KB}(26,32,33)$, AKT $(21,34)$, p38 MAPK $(34,35)$, ERK $(35,36)$ and Wnt/ $\beta$-catenin (4-9) signaling pathways are activated in a number of PEL cell lines, which are necessary for PEL cell survival and proliferation. Therefore, the present study examined whether derivative \#5 affected these pathways. The KSHV-infected PEL cell lines (BC2, JSC1, BC3 and BCBL1) were treated with derivative \#5 for 8-24 h, and cell lysates from harvested cells were subjected to western blot analysis. 

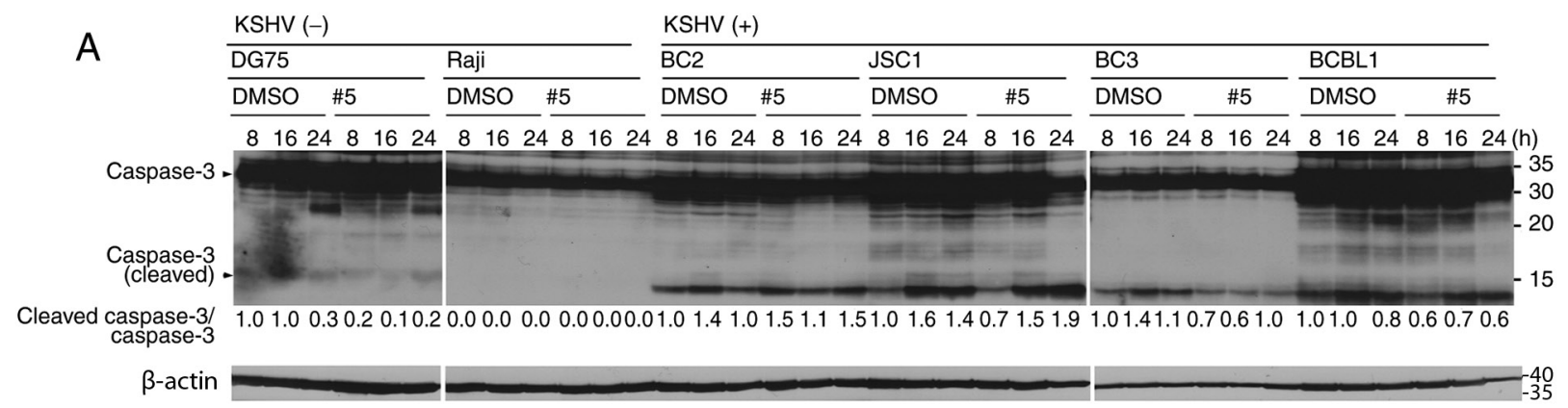

B
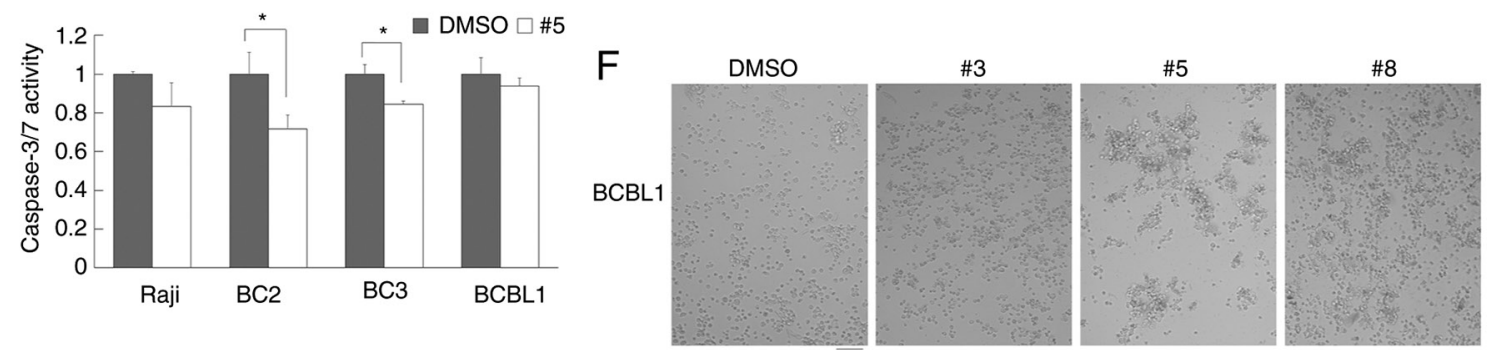

C
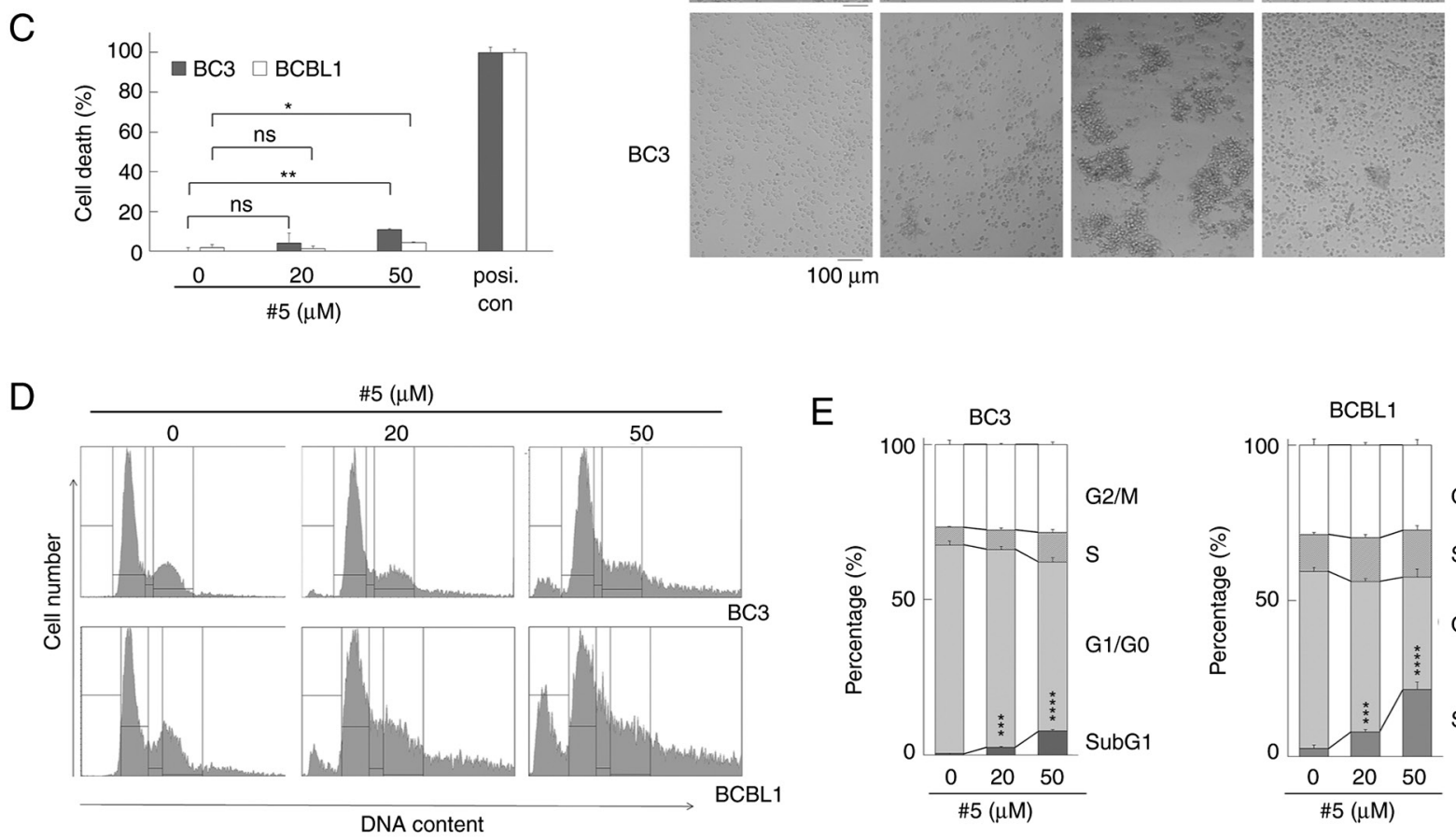

E
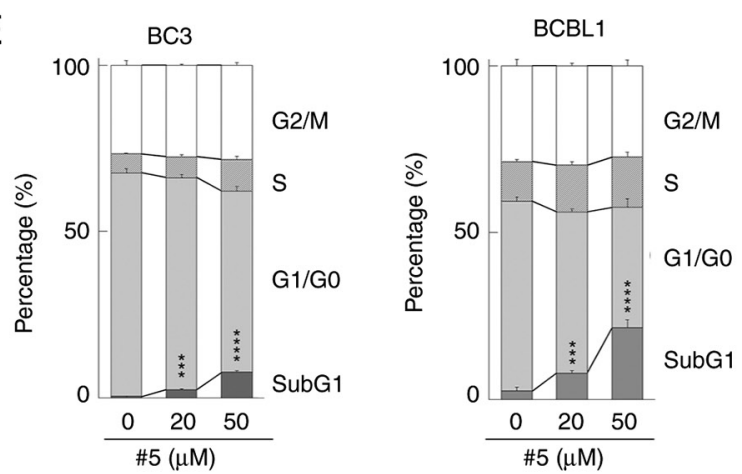

Figure 3. Treatment with derivative \#5 induces PEL cell clumping. (A) Western blot analysis using anti-caspase-3 antibody. PEL cells (BC2, JSC1, BC3 and BCBL1) and uninfected DG75 and Raji cells were incubated with $20 \mu \mathrm{M}$ of derivative \#5 or DMSO (vehicle) for 8-24 h. The western blotting experiments the results of which are depicted were performed twice using independent samples. (B) The proteolytic activities of caspase-3/7 in PEL cells (BC2, BC3 and BCBL1) and KSHV-uninfected Raji cells treated with derivative \#5. Cells were incubated with $20 \mu \mathrm{M}$ of derivative \#5 for $8 \mathrm{~h}$, and the activities of caspase-3/7 in cell lysates were measured using a luciferin-conjugated polypeptide substrate. Caspase-3/7 activity in untreated cells was defined as 1.0 relative light unit. (C) Quantification of dead cells using LDH assay. Cells were incubated with $20 \mu \mathrm{M}$ of derivative $\# 5$ for $24 \mathrm{~h}$, and the number of dead cells was measured using LDH assay. The absorbance of cells treated with a detergent (positive control) was defined as $100 \%$. (B and C) Data are representative of at least three independent experiments. (D) Derivative \#5 increased the sub-G1 fraction in PEL cells in a concentration-dependent manner. To analyze the cell cycle and the sub-G1 including dead cells, the DNA amount of derivative \#5-treated PEL cells were measured using flow cytometry. (E) The distribution of cell cycle phases was calculated based on the flow cytometer data. (F) The increase in cell clumping induced by treatment with derivatives \#3, \#5 and \#8. Cells were cultured with $20 \mu \mathrm{M}$ of derivative $\# 5$ for $24 \mathrm{~h}$. Phase-contrast images were obtained using an inverted microscope. ${ }^{*} \mathrm{P}<0.05,{ }^{* * *} \mathrm{P}<0.005,{ }^{* * *} \mathrm{P}<0.0005$ and ${ }^{* * * * *} \mathrm{P}<0.00005$, statistically significant difference compared with the control group (or DMSO-treated group). ns, not significant; PEL, primary effusion lymphoma; LDH, lactate dehydrogenase.

No changes were detected in the phosphorylation status of AKT, ERK1/2, p38 MAPK and GSK-3 $\beta$ (Fig. 4A). Moreover, the levels of T705-phospho-STAT3, NF-кB and IкB $\alpha$ were not changed in derivative \#5-treated PEL cells (Fig. S2A).
However, the expression level of $\beta$-catenin was decreased in the derivative \#5-treated PEL cell lines. The HBL6 cells exhibited a low expression of $\beta$-catenin compared with the other PEL cell lines (Fig. S2B). This may be due to differences 
A

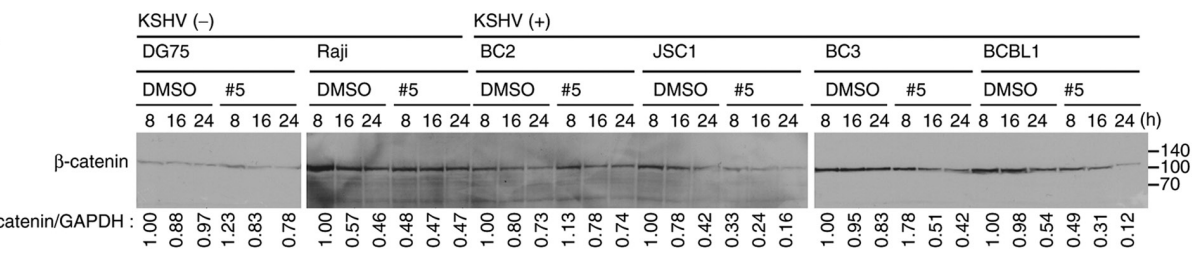
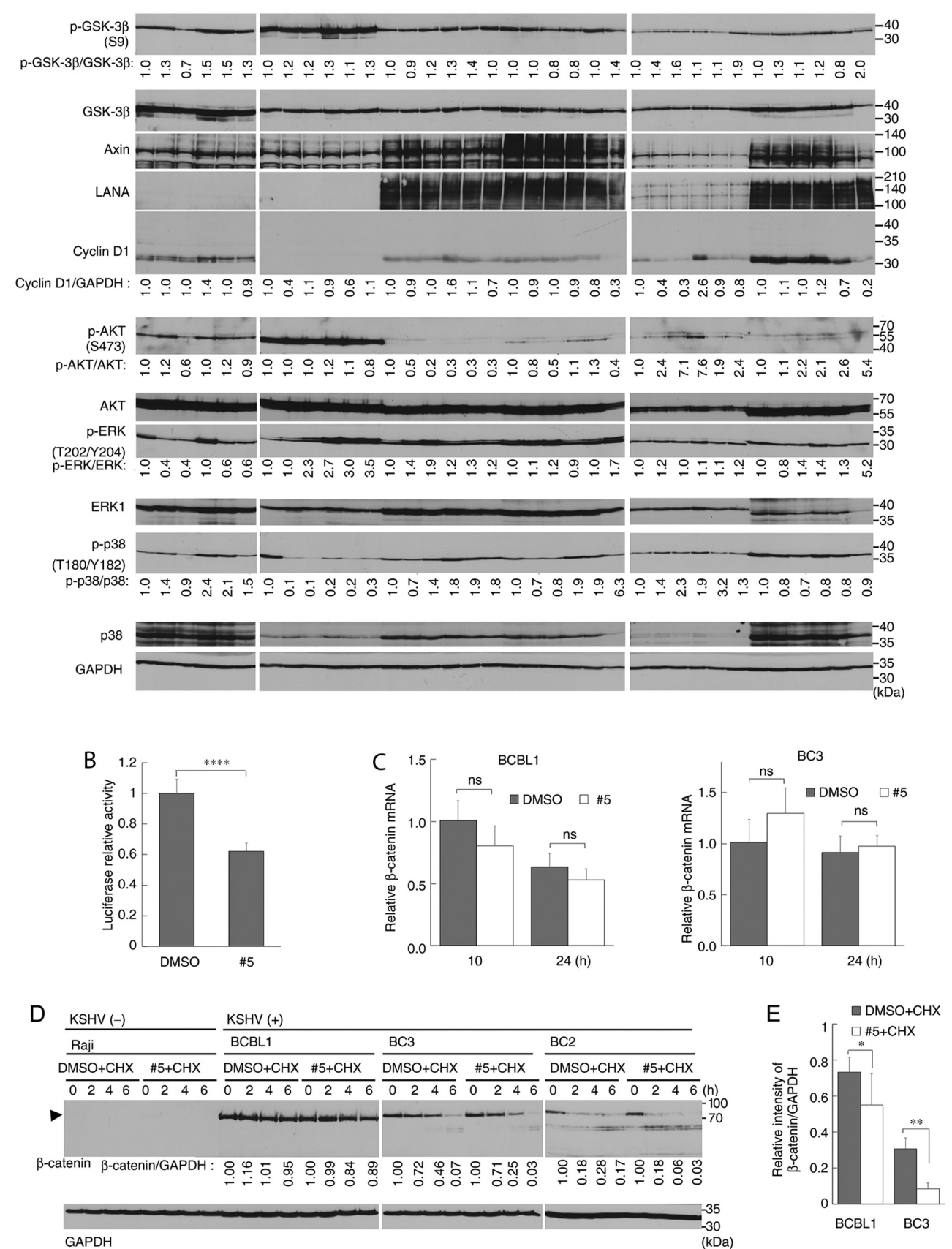

Figure 4. Derivative \#5 downregulates Wnt signaling in PEL cells via $\beta$-catenin destabilization. (A) Downregulation of $\beta$-catenin by treatment of PEL cells with derivative \#5. PEL (BC2, JSC1, BC3 and BCBL1) and KSHV-uninfected (Raji and DG75) cells were treated with $20 \mu \mathrm{M}$ of derivative \#5 for 8-24 h, and cell lysates were examined using western blot analysis. Derivative \#5-treated and DMSO-treated cells are denoted as \#5 and DMSO, respectively. The values of $\beta$-catenin/GAPDH are presented at the bottom of the blots. The value of each DMSO-treated cell line (treated for $8 \mathrm{~h}$ ) was defined as 1.0. The western blotting experiments the results of which are depicted were performed twice using independent samples. (B) Derivative \#5-mediated inhibition of Wnt signaling-induced transcriptional activation. BC3 cells were transfected with the TCF4- $\beta$-catenin reporter plasmid (GL3-OT), and transfected cells were cultured in media containing $20 \mu \mathrm{M}$ of derivative \#5 or DMSO for $24 \mathrm{~h}$. The luciferase activity of DMSO-treated transfected BC3 cells was defined as 1.0. (C) Effect of derivative \#5 on $\beta$-catenin mRNA expression. Cells were treated with $20 \mu \mathrm{M}$ of derivative \#5, and total RNA was subjected to reverse transcription-quantitative PCR. The values obtained from DMSO-treated cells (treated for $10 \mathrm{~h}$ ) were defined as 1.0. (B and C) Results are presented as the mean \pm SD $(\mathrm{n}=3)$. (D) Effect of derivative $\# 5$ on $\beta$-catenin stabilization. Cells were cultured for $0-6 \mathrm{~h}$ in media with $20 \mu \mathrm{M}$ derivative $\# 5$ in the presence of $50 \mu \mathrm{g} / \mathrm{ml}$ CHX. The values of $\beta$-catenin/GAPDH in DMSO-treated cells at $0 \mathrm{~h}$ was defined as 1.0. (E) Quantitative analysis of $\beta$-catenin expression in derivative \#5-treated PEL cells. Cells were incubated with $20 \mu \mathrm{M}$ derivative \#5 in the presence of $50 \mu \mathrm{g} / \mathrm{ml} \mathrm{CHX}$ for 0 or $6 \mathrm{~h}$. Cell lysates prepared by three independent experiments were examined using western blot analysis. The blotting images are shown in Fig. S3. The value of derivative \#5 (or DMSO)-treated cells for $0 \mathrm{~h}$ was defined as 1.0. ${ }^{*} \mathrm{P}<0.05,{ }^{* *} \mathrm{P}<0.005$ and ${ }^{* * * *} \mathrm{P}<0.00005$, statistically significant difference compared with the control group (or DMSO-treated group). ns, not significant; PEL, primary effusion lymphoma; GSK-3 $\beta$, glycogen synthase kinase $3 \beta$; LANA, latency-associated nuclear antigen; CHX, cycloheximide. 
in the genetic background or differentiation status of the tested cells. In order to confirm the suppression of Wnt/ $\beta$-catenin signaling in derivative \#5-treated PEL cells, a reporter assay was performed using the TCF4- $\beta$-catenin reporter (GL3-OT) plasmid. As was expected, the Wnt/ $\beta$-catenin transcriptional activity of the $\mathrm{BC} 3$ cells was significantly decreased to $60 \%$ upon treatment with derivative \#5 (Fig. 4B). Since the cyclin D1 gene (CCND1) is one of the target genes of $\mathrm{Wnt} / \beta$-catenin signaling, the expression of cyclin D1 was monitored in the derivative \#5-treated PEL cells. As was expected, treatment with derivative \#5 decreased cyclin D1 expression in the PEL cells (Fig. 4A).

In order to determine whether the derivative \#5-mediated downregulation of $\beta$-catenin is due to its transcriptional inactivation or its protein destabilization, the mRNA expression levels of $\beta$-catenin and $\beta$-catenin protein stability were examined in derivative \#5-treated PEL cells. The mRNA expression of $\beta$-catenin in the $\mathrm{BC} 3$ or BCBL1 cells treated with derivative \#5 was monitored using RT-qPCR (Fig. 4C). Derivative \#5 treatment slightly reduced the mRNA expression of $\beta$-catenin in the BCBL1 cells. Subsequently, a CHX chase analysis was conducted in order to determine whether derivative \#5 induced the destabilization of $\beta$-catenin. $\mathrm{CHX}$ was used to inhibit de novo protein synthesis. In this experiment, the cells were cultured in medium with or without derivative \#5 in the presence of $50 \mu \mathrm{g} / \mathrm{ml} \mathrm{CHX}$. The cells were harvested at 2-6 h. The results indicated that derivative \#5 induced the destabilization of $\beta$-catenin protein in PEL cells as compared with the vehicle control (Fig. 4D). To obtain further evidence, the quantitative analysis of $\beta$-catenin expression in derivative \#5-treated PEL cells was performed using three independent experiments. The BCBL1 and BC3 cells were incubated with $20 \mu \mathrm{M}$ derivative \#5 (or DMSO) with $50 \mu \mathrm{g} / \mathrm{ml} \mathrm{CHX}$ for 0 or $6 \mathrm{~h}$. The destabilization of $\beta$-catenin was then examined using western blot analysis (Fig. S3). The data indicated that derivative \#5 induced $\beta$-catenin destabilization in PEL cells (Fig. 4E).

Derivative \#5 enhances the phosphorylation of $\beta$-catenin at Ser33/Ser37/Thr41. The mechanism of $\beta$-catenin degradation consists of three sequential steps $(37,38)$ : i) The phosphorylation of $\beta$-catenin at Ser33/Ser37/Thr41 by GSK-3 $\beta$; ii) the polyubiquitination of Ser33/Ser37/Thr41-phosphorylated $\beta$-catenin by E3 ubiquitin ligase; and iii) the degradation of polyubiquitinated $\beta$-catenin by the $26 \mathrm{~S}$ proteasome. The present study therefore attempted to determine which step was affected by derivative \#5, which leads to $\beta$-catenin destabilization (Fig. 5A-E). It was found that the levels of GSK-3 $\beta$ and Ser9-phosphorylated GSK-3 $\beta$ (i.e., the inactive form of GSK-3 $\beta$ ) were not altered in the B-lymphoma and PEL cells following treatment with derivative \#5 (Fig. 4A). Thus, the present study also evaluated whether derivative \#5 affected $26 \mathrm{~S}$ proteasome activity. No differences in the protease activity of the $26 \mathrm{~S}$ proteasome were found between the derivative \#5-treated and untreated cells (Fig. 5A). On the other hand, it was previously found that KSHV LANA interacted with GSK-3 $\beta$ in the nucleus, leading to $\beta$-catenin stabilization and subsequent activation of $\mathrm{Wnt} / \beta$-catenin signaling in KSHV-infected cells including PEL cells (6-9). GSK-3 $\beta$ is localized primarily in the cytoplasm, and GSK-3 $\beta$ phosphorylates the cytoplasmic $\beta$-catenin for the destabilization of $\beta$-catenin. GSK-3 $\beta$ is known to enter the nucleus during the $S$ phase, and LANA increases the number of cells in the $S$ phase and binds to nuclear GSK-3 $\beta$ (6-9). Therefore, the present study examined the effects of derivative \#5 on GSK-3 $\beta$-mediated $\beta$-catenin destabilization, as well as LANA-mediated $\beta$-catenin stabilization. As was expected, co-transfection of plasmids encoding GSK-3 $\beta$ and $\beta$-catenin resulted in the loss of detectable $\beta$-catenin in the HeLa cells (Fig. 5B). Furthermore, in the presence of LANA, the ability of GSK-3 $\beta$ to promote $\beta$-catenin destabilization was markedly decreased, and $\beta$-catenin was easily detectable. These results are in agreement with those of previous studies $(6,7)$. This LANA-mediated $\beta$-catenin stabilization was partially overcome by treatment with derivative \#5. Moreover, in the absence of LANA and GSK-3 $\beta, \beta$-catenin was also destabilized by derivative \#5.

Subsequently, the effects of derivative \#5 on the phosphorylation and polyubiquitination of $\beta$-catenin were analyzed. Of note, the data indicated that derivative \#5 induced the Ser33/Ser37/Thr41 phosphorylation of exogenous and endogenous $\beta$-catenin (Fig. 5C and D). The destabilization of $\beta$-catenin was detected by $6 \mathrm{~h}$ of treatment with derivative \#5 (Fig. 5B); however, the destabilization of $\beta$-catenin was not detected by 2 and $4 \mathrm{~h}$ of treatment with derivative \#5 (Fig. 5C). These results may be due to different durations of treatment with derivative \#5. As indicated in Fig. 4A, treatment with derivative \#5 for 2-4 h was not sufficient to induce $\beta$-catenin destabilization. In addition to phosphorylation, derivative \#5 increased the endogenous polyubiquitination of $\beta$-catenin in BC3 cells (Fig. 5E). Since LANA interacts with GSK-3 $\beta$ in the nucleus, leading to $\beta$-catenin stabilization in PEL cells, the present study determined whether derivative \#5 affected the interaction and the nuclear co-localization of LANA and GSK-3 $\beta$. The Co-IP data confirmed the interaction of GSK-3 $\beta$ and LANA in co-transfected cells (Fig. 5F). However, derivative \#5-treatment did not affect the interaction of GSK-3 $\beta$ and LANA. In addition to the interaction, the effect of derivative \#5 on the nuclear co-localization of GSK-3 $\beta$ and LANA was evaluated by IFA (Fig. 5G). The data revealed the nuclear co-localization of GSK-3 $\beta$ (green) and LANA (red) in co-transfected cells; however, derivative \#5 did not affect the nuclear co-localization of GSK-3 $\beta$ and LANA. The data demonstrated that GSK-3 $\beta$ markedly induced $\beta$-catenin destabilization, and KSHV LANA stabilized $\beta$-catenin even in the presence of GSK-3 $\beta$. Moreover, it was found that derivative \#5 induced the phosphorylation and polyubiquitination of $\beta$-catenin, which overcame LANA-mediated $\beta$-catenin stabilization. However, derivative \#5 did not affect the interaction and the nuclear co-localization of GSK-3 $\beta$ and LANA.

Derivative \#5 abrogates PEL tumor cell development in SCID mice. Since derivative \#5 was cytotoxic against PEL cell lines (Fig. 1), the present study then investigated whether derivative \#5 exerted cytotoxic effects against xenograft PEL cells in SCID mice. BCBL1 PEL cells were injected intraperitoneally into SCID mice twice (10 days and 1 day prior to the commencement of derivative \#5 administration), and PEL-xenografted mice (PEL-mice) were 
A

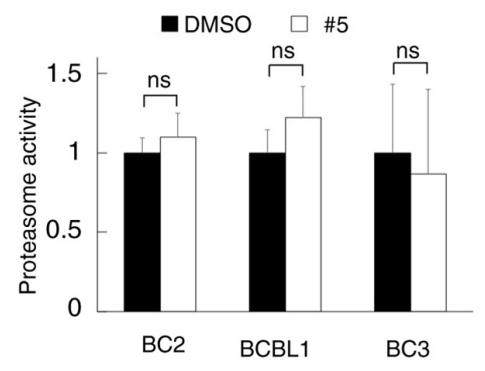

B
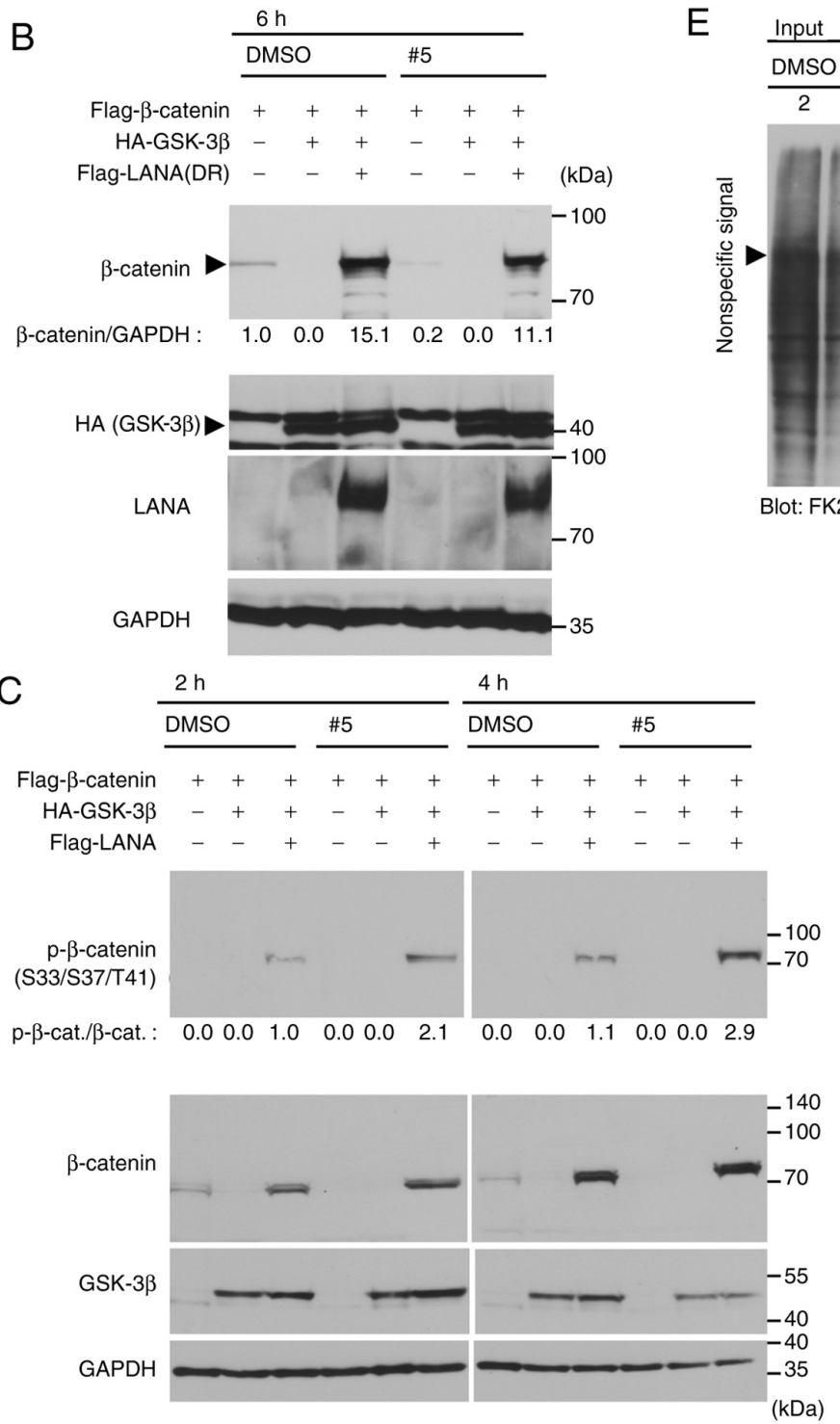

D $\frac{\text { DMSO }}{8 \quad 1624} \frac{\# 5}{8 \quad 1624(h)}$

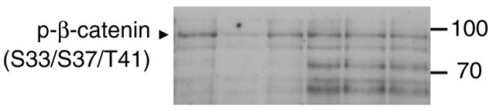

p- $\beta$-catenin/ $\beta$-catenin : $1.0 \quad 0.20 .91 .41 .51 .7$

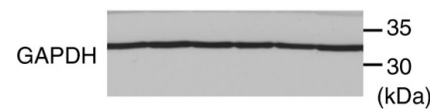

E
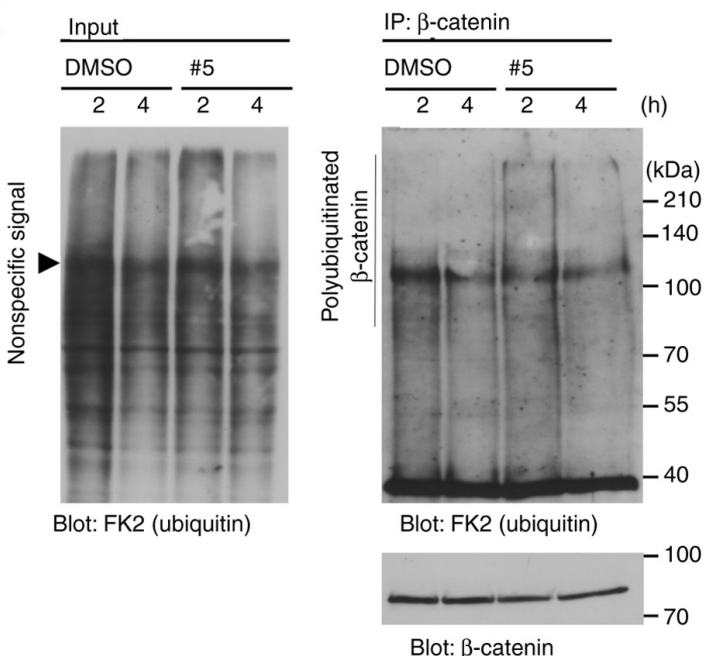

$\mathrm{F}$

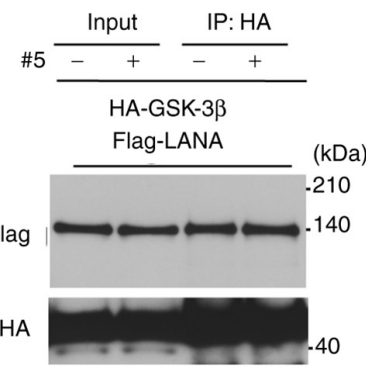

G

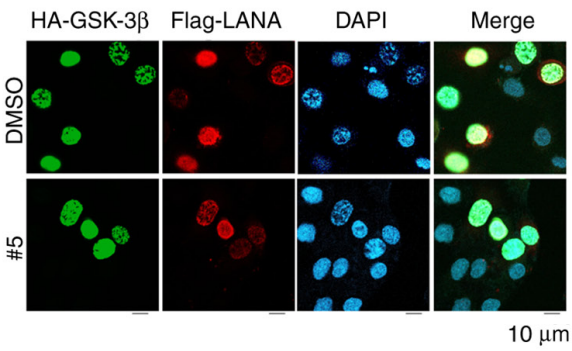

Figure 5. Derivative \#5 induces $\beta$-catenin destabilization by increasing the phosphorylation of $\beta$-catenin at Ser33/Ser37/Thr41. (A) Effects of derivative \#5 on the proteasomal chymotrypsin-like activity in PEL cells. Cells were cultured with $20 \mu \mathrm{M}$ derivative $\# 5$ or DMSO for $24 \mathrm{~h}$. The proteasome activities of the cell lysates were evaluated using a fluorometric assay with a synthetic peptide. The proteasome activity of DMSO-treated cells was defined as 1.0. The results are presented as the mean $\pm \mathrm{SD}(\mathrm{n}=3)$. (B) Derivative \#5 destabilized $\beta$-catenin and overcame LANA-mediated $\beta$-catenin stabilization. HeLa cells were co-transfected with $1 \mu \mathrm{g}$ Flag- $\beta$-catenin, $0.2 \mu \mathrm{g}$ HA-GSK-3 $\beta, 0.3 \mu \mathrm{g}$ Flag-LANA (dR) and empty pCIneo (for adjusting to $1.5 \mu \mathrm{g}$ as the total amount) plasmids. The cells were then treated with $20 \mu \mathrm{M}$ derivative \#5 and $100 \mu \mathrm{g} / \mathrm{ml}$ cycloheximide for $6 \mathrm{~h}$. (C) Derivative \#5 induced the phosphorylation of $\beta$-catenin at Ser33/Ser37/Thr41. HeLa cells were co-transfected with $1 \mu \mathrm{g}$ Flag- $\beta$-catenin, $0.2 \mu \mathrm{g}$ HA-GSK-3 $\beta, 0.3 \mu \mathrm{g}$ Flag-LANA (dR) and empty plasmids. The cells were then treated with $20 \mu \mathrm{M}$ derivative \#5 and $100 \mu \mathrm{g} / \mathrm{ml}$ cycloheximide. (D) Derivative \#5 induced the phosphorylation of $\beta$-catenin at Ser33/Ser37/Thr41 in BC3 PEL cells. The cell lysates, which were same as the lysates used in Fig. 4A, were used. The lysates were prepared from cells treated with $20 \mu \mathrm{M}$ derivative \#5 and subjected to western blot analysis. The data of band intensities of $\beta$-catenin in Fig. $4 \mathrm{~A}$ were used to calculate the $\mathrm{p}-\beta$-catenin/ $\beta$-catenin ratio. (E) Derivative $\# 5$ induced the polyubiquitination of endogenous $\beta$-catenin. BC3 cells were treated with $20 \mu \mathrm{M}$ derivative \#5 and $10 \mu \mathrm{M}$ MG132 for 2 or $4 \mathrm{~h}$. The cell extracts were incubated with anti- $\beta$-catenin antibody-immobilized beads, and immunoprecipitated (IP) $\beta$-catenin was subjected to western blot analysis with anti-polyubiquitin antibody (FK2) to detect the polyubiquitinated $\beta$-catenin. The western blotting experiments the results of which are depicted were performed twice using independent samples. (F) Effect of derivative \#5 on the interaction between KSHV LANA and GSK-3 $\beta$. HeLa cells were co-transfected with Flag-LANA (dR) and HA-GSK-3 $\beta$ and then treated with $20 \mu \mathrm{M}$ derivative $\# 5$ for $10 \mathrm{~h}$. HA-GSK-3 $\beta$ was immunoprecipitated from cell extracts with anti-HA antibody-immobilized beads (IP: HA), and the immunoprecipitate was probed by anti-Flag antibody. (G) Effect of derivative \#5 on nuclear colocalization of GSK-3 $\beta$ and LANA. HeLa cells were co-transfected with Flag-LANA (dR) and HA-GSK-3 $\beta$ plasmids and treated with $20 \mu \mathrm{M}$ derivative $\# 5$ for $10 \mathrm{~h}$. The localization of Flag-LANA (red) and HA-GSK-3 $\beta$ (green)

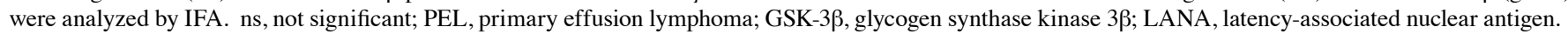


established. The corn oil emulsions of derivative \#5 or the vehicle control (DMSO) were injected intraperitoneally into PEL-mice or normal mice once per 2 (or 3) days for 3 weeks. The PEL-xenografted mice with and without derivative \#5 administration differed significantly in their gross appearance (Fig. 6A and B): The abdomen of the DMSO-treated PEL-mice exhibited abdominal expansion, whereas the derivative \#5-treated mice had an apparently normal body shape. The increase in the body weight of the derivative \#5-treated PEL-mice was less marked than that of the DMSO-treated PEL-mice. Moreover, the body weight curves of the derivative \#5- and DMSO-treated non-xenografted mice (normal mice) exhibited a similar trend. These data indicated that derivative \#5 had a low toxicity in both the mouse model and the in vitro model using PBMCs (Fig. 2K). Murine autopsies demonstrated that the spleens of DMSO-treated PEL-mice exhibited distention compared to spleens from the derivative \#5-treated PEL-mice (Fig. 6C). It has been previously reported that PEL-xenografted SCID mice exhibit spleen distention (26), which is in agreement with the present data. The weight of the spleen in the derivative \#5-treated group was $\sim 0.15 \mathrm{~g}$, which was lower $(\sim 0.4 \mathrm{~g})$ than that of the DMSO-treated group (Fig. 6D). By contrast, the livers of the derivative \#5- and DMSO-treated mice appeared normal and were similar in morphology. In addition, the weight of the tumor cells in the ascites of the derivative \#5-treated group was significantly lower than that of the DMSO-treated group (Fig. 6D). IFA confirmed that the tumor cells in the ascites of DMSO-treated PEL-mice were derived from administered BCBL1 cells as these tumor cells expressed LANA, a marker of KSHV latent infection (Fig. 6E). These results indicated that xenograft BCBL1-derived tumor cells developed in the ascites of DMSO-treated control mice, and that derivative \#5 prevented BCBL1-derived tumor cell development in the ascites.

Derivative \#5 does not affect the KSHV latent infection of PEL cells and does not induce lytic replication. In KSHV lytic replication $(4,5)$, virions are produced in PEL cells and are subsequently released, resulting in cell death. During reactivation, lytic genes are expressed in an orderly manner and are sequentially expressed. The lytic genes are divided into three transcriptional stages: Immediate early, early and late. KSHV lytic replication is triggered by the expression of the replication transcription activator (RTA)/ORF50, which is an immediate early gene product and viral transcription factor that transcriptionally activates the early genes, such as k-bZip (5). In the present study, since the viability of the PEL cells were decreased to $\sim 50 \%$ following treatment with derivative \#5 (Fig. 2E), it was then determined whether derivative \#5 induces lytic replication in KSHV latently infected BC3 (Fig. 7A) and BCBL1 (Fig. 7B) cells. It was found that treatment with $20 \mu \mathrm{M}$ of derivative \#5 did not induce the mRNA expression of the immediate early gene, RTA/ORF50, nor that of the early gene, k-bZip. Furthermore, in the BC3 and BCBL1 cells, derivative \#5 did not influence the transcription of the latent genes, LANA and v-IL6. These results indicated that derivative \#5 suppressed proliferation of PEL cells without the production of nascent virus.

\section{Discussion}

The authors previously reported that a pyrrolidinium-type fullerene (derivative \#1) induced the generation of ROS (16) and exhibited anti-viral activities by inhibiting viral enzymes such as HIV RT (19), HCV NS5B (19) and influenza virus endonuclease (20). It was also found that derivative \#1 suppressed PEL cell proliferation by interfering with the phosphorylation of AKT and procaspase-9 (21). Therefore, the present study focused on the cation-functionalized moiety of derivative \#1 and evaluated other cationic fullerene derivatives containing pyrrolidinium, pyridinium or anilinium (derivatives \#2-\#9) (16,17,19,21,23-25). All the derivatives suppressed the growth of not only PEL cell lines, but also that of KSHV-uninfected B cell lines. In addition, derivatives \#5,\#6,\#8 and \#9 tended to decrease the number of viable KSHV-infected PEL cells compared with the KSHV-uninfected cells (Fig. 2). In addition, among the tested derivatives, derivatives \#5 and \#6 exerted potent growth inhibitory effects against PEL cells. Considering the consensus structure of derivative \#5 and \#6, it was hypothesized that the pyrrolidine ring of fullerene needs to possess one 3-N-methylpyridinium (or 3-N-ethylpyridinium) moiety and one $\mathrm{COOC}_{2} \mathrm{H}_{5}$ moiety at the appropriate position in order to exert selective and potent antitumor activity against PEL cells.

To reveal the mechanisms through which derivative \#5 decreases PEL cell viability, the cleavage and activation of caspases was evaluated. However, both were not detected in PEL cells treated with derivative \#5 (Fig. 3A and B). The cell cycle analysis and $\mathrm{LDH}$ assay disclosed that derivative \#5 increased the number of dead cells and the cells with a sub-G1 DNA content (Fig. 3C-E). These findings suggested that the derivative \#5 induced caspase-independent cell death and decreased PEL cell viability. On the other hand, derivatives \#5, \#3 and \#8 formed cell clumps of KSHV-infected PEL and uninfected B cells. Of note, derivative \#5 prominently induced cell-to-cell clumping (Figs. 3F and S1). It was hypothesized that there may be an association between cell clumping formation and cell death induced by derivative \#5. However, the mechanisms of fullerene-dependent clumping remain unclear and warrant further investigation in future studies.

In the present study, it was discovered that derivative \#5 exhibited preferential cytotoxic activity against KSHV latently infected PEL cells compared with KSHV-uninfected B cells. KSHV constitutively activates $\mathrm{Wnt} / \beta$-catenin signaling in PEL cells (4-9), which may be related to the higher sensitivity of PEL cells to derivative \#5. The KSHV-uninfected cells were less sensitive to derivative \#5, which may be explained by their Wnt/ $\beta$-catenin signaling-independent cell proliferation. The results indicated that derivative \#5 suppressed $\mathrm{Wnt} / \beta$-catenin signaling in PEL cells thorough the destabilization of $\beta$-catenin. To the best of our knowledge, this is the first study to describe the dysregulation of $\mathrm{Wnt} / \beta$-catenin signaling by a water-soluble fullerene derivative.

Wnt signaling is involved in several critical developmental processes and in tumorigenesis. The Wnt/ $\beta$-catenin pathway regulates the availability of nuclear $\beta$-catenin (37) (Fig. 8). In the absence of Wnt signaling, $\beta$-catenin is held in a complex with Axin, APC, and GSK-3 $\beta$. The Axin-APC complex 
A

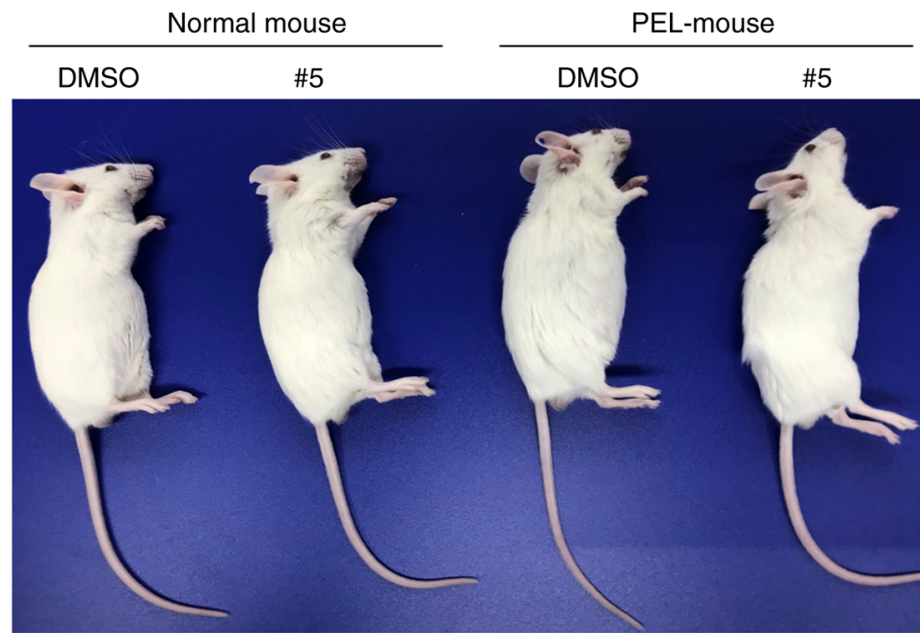

$\mathrm{B}$

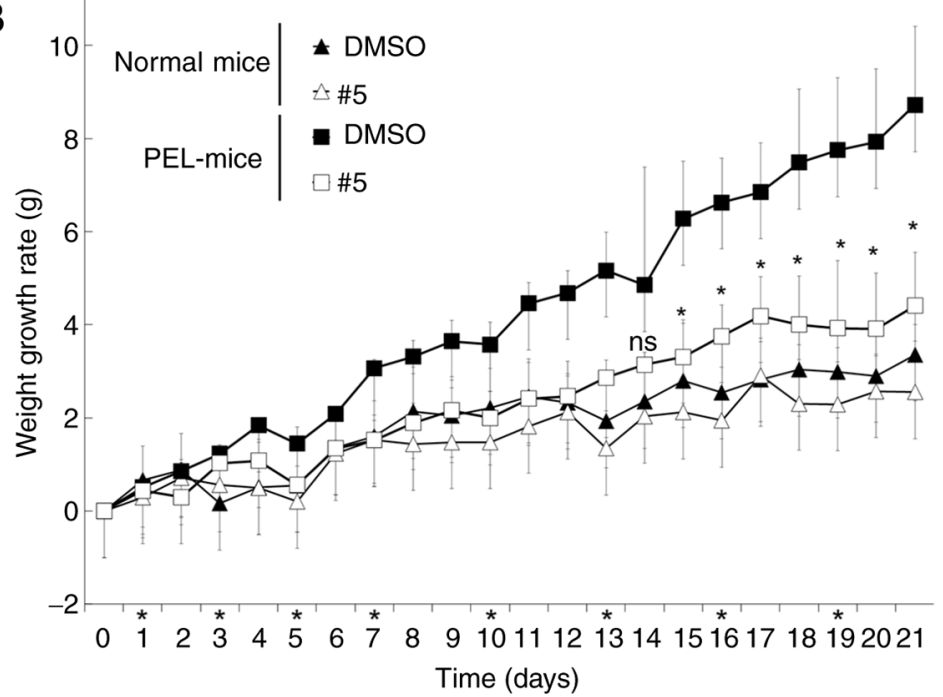

C

$\begin{array}{lll}\text { Normal mouse } & & \text { PEL-mouse } \\ & \text { DMSO \#5O \#5 }\end{array}$

Liver

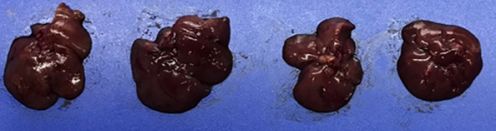

Spleen

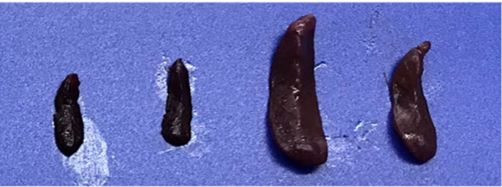

D
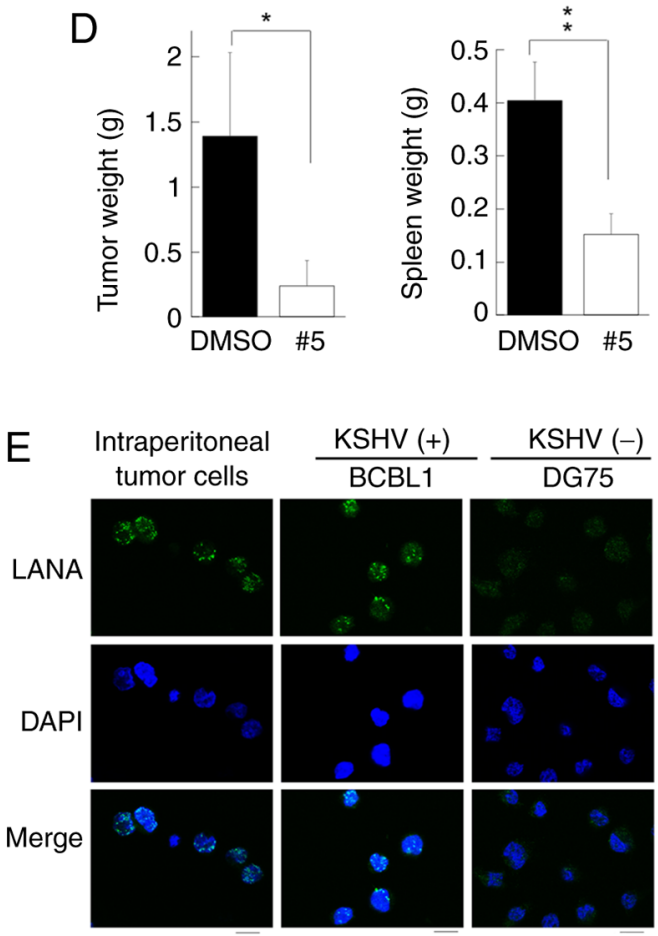

$10 \mu \mathrm{m}$

Figure 6. In vivo effects of derivative \#5 in PEL-xenografted SCID mice. (A) Photograph showing derivative \#5-treated (right) and DMSO (vehicle)-treated (left) SCID mice on day 21 following PEL cell transplantation (PEL-mouse). To establish PEL-xenografted mice (PEL-mice), BCBL1 cells were injected intraperitoneally into SCID mice twice (10 days and 1 day prior to the commencement of derivative $\# 5$ administration). Derivative \#5 or DMSO dissolved in corn oil was intraperitoneally administered into PEL-mice or normal mice at a dose of $20 \mathrm{mg} / \mathrm{kg}$ body weight every 2 days for the first 1 week and subsequently every 3 days for the following 2 weeks. (B) Changes in the body weight of the BCBL1-xenografted SCID mice at 21 days from the commencement of derivative \#5 administration. The asterisks $\left(^{*}\right)$ on the $\mathrm{x}$ axis indicate the day of administration. The changes in the body weight of the DMSO-administered normal mice $(n=3)$ are indicated by black triangles and those of derivative $\# 5$-administered normal mice $(n=3)$ are indicated by white triangles. Moreover, the changes in the body weight of DMSO-administered PEL-mice $(\mathrm{n}=3)$ are indicated by black squares and those of derivative \#5-administered PEL-mice $(\mathrm{n}=3)$ are indicated by white squares. (C) Image showing the livers and spleens of derivative \#5-treated or DMSO-treated PEL-mice and derivative \#5-treated or DMSO-treated normal mice. (D) Intraperitoneal tumor weight and spleen weight of derivative \#5-treated or DMSO-treated PEL-mice. The tumor cells were separated from the ascites by centrifugation, and the tumor weight was measured. The wet weight of the obtained precipitate was regarded as the tumor weight. The results are presented as mean $\pm \mathrm{SD}(\mathrm{n}=3)$. (E) LANA expression in ascites cells from DMSO-treated PEL-mice. The ascites cells derived from DMSO-treated PEL-mice were analyzed by IFA using anti-LANA antibody. BCBL1 and DG75 cells were also observed as a positive and negative control, respectively. "P<0.05 and ${ }^{* *} \mathrm{P}<0.005$, statistically significant difference compared with the control group (or DMSO-treated group). ns, not significant; PEL, primary effusion lymphoma; LANA, latency-associated nuclear antigen; KSHV, Kaposi's sarcoma-associated herpesvirus.

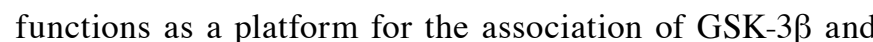
$\beta$-catenin. Phosphorylated $\beta$-catenin is conjugated to polyubiquitin and then degraded by the $26 \mathrm{~S}$ proteasome $(37,38)$. The Wnt signaling cascade is triggered when the Wnt ligand binds to the Frizzled receptor, which leads to downregulation of the Axin-APC-GSK-3 $\beta$ complex through Dvl, LRP and FRAT. Subsequently $\beta$-catenin is stabilized and it translocates to the nucleus and forms a complex with the transcription factor TCF4. The complex of $\beta$-catenin and TCF4 transcriptionally activates specific target genes $(C C N D 1, c-M Y C$, etc.) $(39,40)$.
Wnt $/ \beta$-catenin signaling is upregulated in various tumors, including colorectal cancer, which has mutations in APC and $\beta$-catenin $(41,42)$. These mutations ultimately result in the stabilization of $\beta$-catenin. The authors previously found that KSHV LANA stabilizes $\beta$-catenin. In KSHV-infected cells, $\beta$-catenin is stabilized by the following mechanisms: i) GSK-3 $\beta$ enters the nucleus during S-phase; ii) LANA binds to nuclear GSK-3 $\beta$; iii) LANA inhibits nuclear export of GSK-3 $\beta$ and GSK-3 $\beta$ accumulates in the nucleus; and iv) the reduced cytoplasmic abundance of GSK-3 $\beta$ allows for the stabilization and 
A DMSO $\square \# 5$
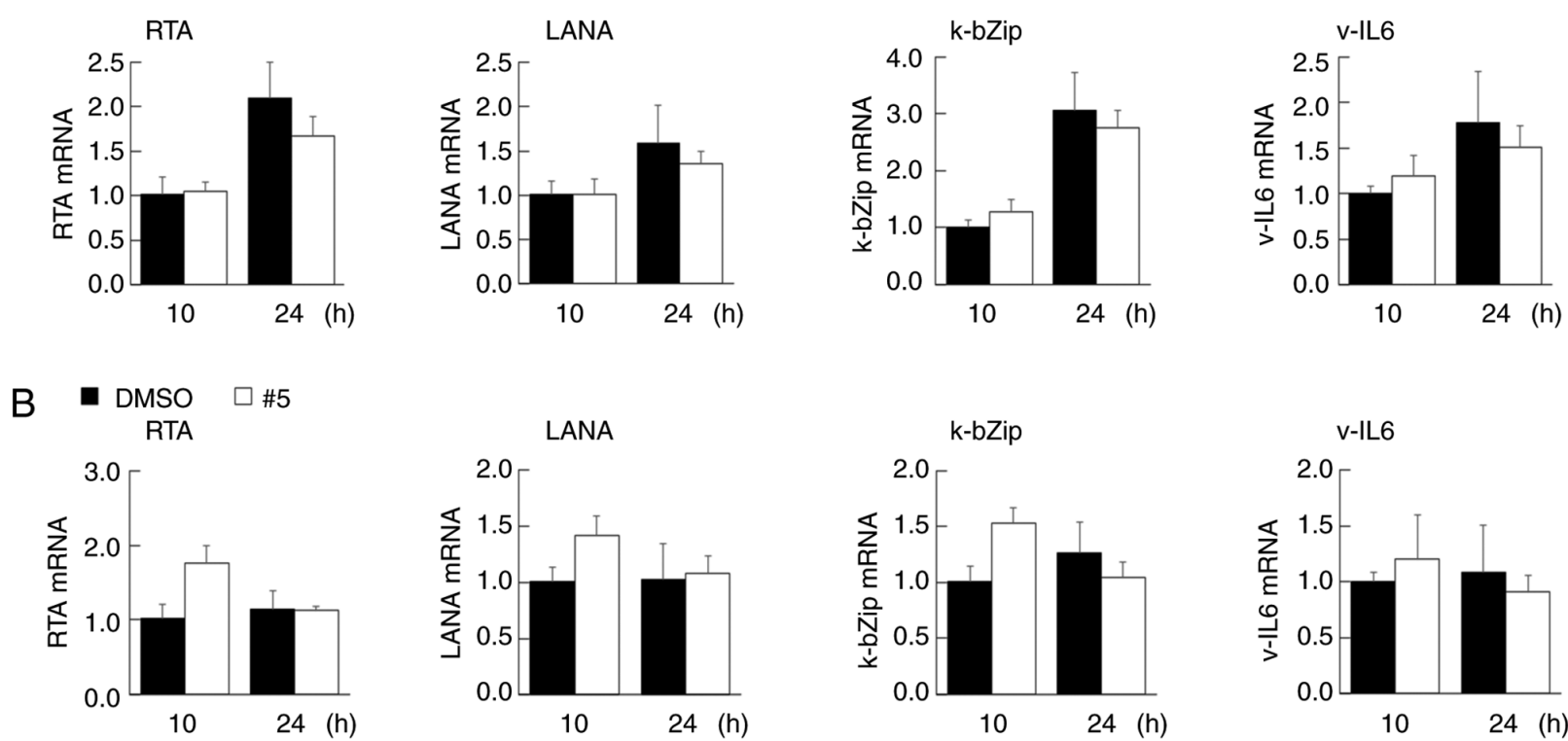

Figure 7. Effect of derivative \#5 on KSHV latent infection in PEL cells. Effect of derivative \#5 on KSHV latent and lytic gene transcription in (A) BC3 and (B) BCBL1 cells. BC3 or BCBL1 cells were cultured for 10 and $24 \mathrm{~h}$ with derivative \#5. Total RNA was extracted from harvested cells and subjected to reverse transcription-quantitative PCR using primers to amplify the lytic genes: RTA (immediate early) and k-bZip (early) as well as the latent genes: LANA and v-IL6. The respective gene expression levels in DMSO (vehicle)-treated cells were defined as 1.0. The results are presented as the mean \pm SD $(n=3)$. LANA, latency-associated nuclear antigen; RTA, replication transcription activator.

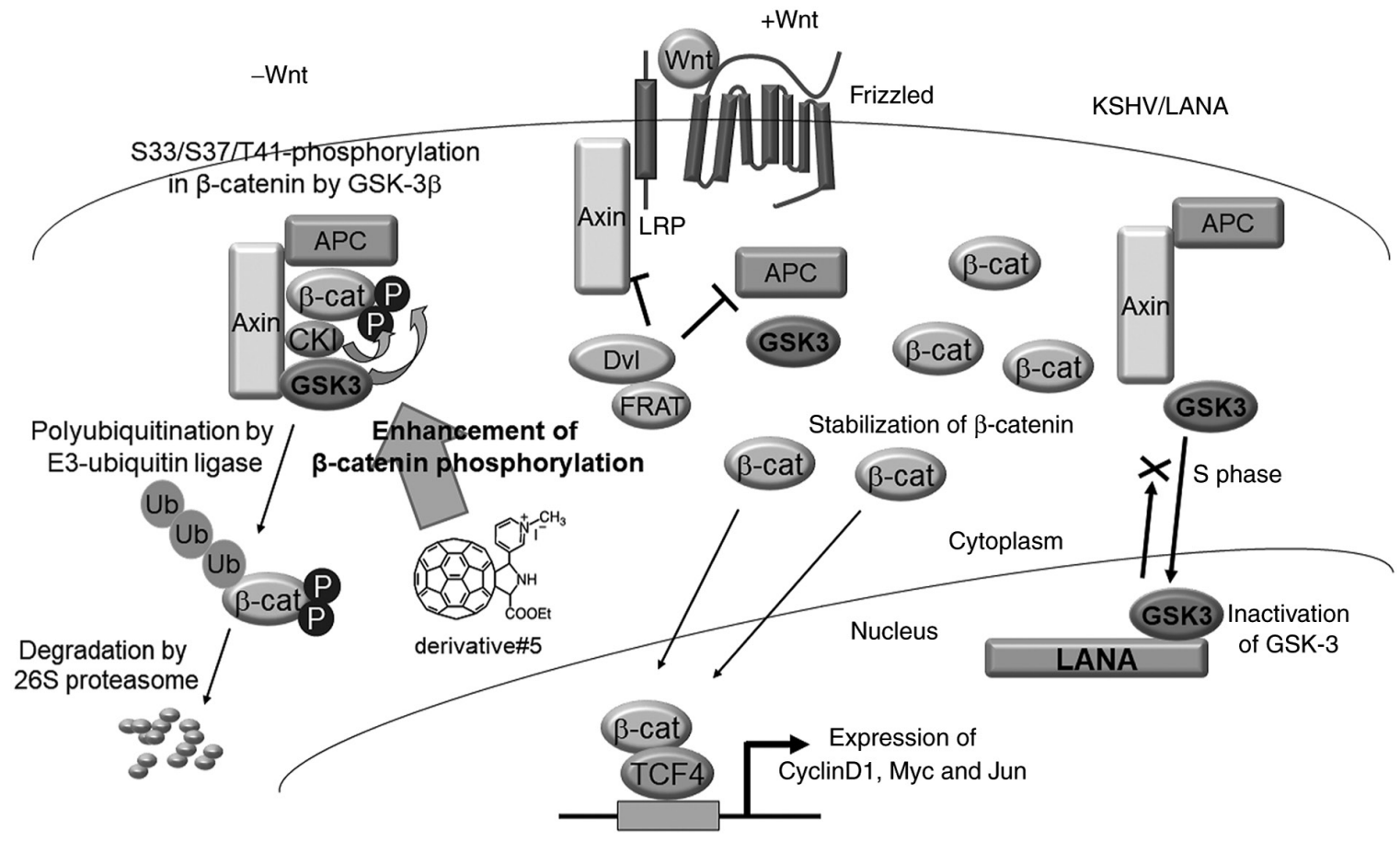

Figure 8. Model of derivative \#5-mediated downregulation of Wnt/ $\beta$-catenin signaling. Under normal conditions or in the absence of Wnt ligand, Wnt $/ \beta$-catenin signaling is downregulated, as $\beta$-catenin is degraded in the following sequential fashion: i) The phosphorylation of $\beta$-catenin at Ser33/Ser37/Thr41 by GSK-3 $\beta$ induces the formation of a complex containing $\beta$-catenin, Axin and APC; ii) the polyubiquitination of the phosphorylated $\beta$-catenin by E3 ubiquitin ligase; and iii) the degradation of polyubiquitinated $\beta$-catenin by the $26 \mathrm{~S}$ proteasome. In the presence of Wnt ligand, $\beta$-catenin is stabilized by Dvl- and LRP-mediated disassociation of a complex containing GSK- $3 \beta$, Axin and APC. In KSHV-infected cells, KSHV LANA interacts with GSK-3 $\beta$ in the nucleus, leading to $\beta$-catenin stabilization and subsequent activation of Wnt/ $\beta$-catenin signaling. Derivative \#5 induces the phosphorylation-dependent destabilization of $\beta$-catenin, leading to downregulation of Wnt/ $\beta$-catenin signaling. APC, adenomatous polyposis coli; CK1, casein kinase $1 ; \beta$-cat, $\beta$-catenin; circled P, phospho; Dvl, Dishevelled; FRAT, frequently rearranged in advanced T-cell lymphomas; GSK3, glycogen synthase kinase-3 3 ; LANA, latency-associated nuclear antigen; circled Ub, ubiquitin; LRP, low-density lipoprotein receptor-related protein and TCF4, T-cell factor and lymphoid enhancer factor.

nuclear entry of $\beta$-catenin (6-9). The present study examined the mechanisms underlying derivative \#5-mediated $\beta$-catenin destabilization. Derivative \#5 did not affect the mRNA expression of $\beta$-catenin (Fig. 4C). Moreover, derivative \#5 
had no effect on the level of GSK-3 $\beta$, on phosphorylation of GSK-3 $\beta$ (Fig. 4A), on 26S proteasome activity (Fig. 5A) and on the interaction of GSK-3 $\beta$ and LANA (Fig. 5F). The data also confirmed that GSK-3 $\beta$ induced $\beta$-catenin destabilization, and LANA stabilized $\beta$-catenin even in the presence of GSK-3 $\beta$. Notably, derivative \#5 induced the phosphorylation of $\beta$-catenin at Ser33/Ser37/Thr41 (Fig. 5C and D), which resulted in the polyubiquitination of $\beta$-catenin and subsequent proteasomal degradation. The data revealed that derivative \#5 overcame LANA-mediated $\beta$-catenin stabilization via the enhancement of $\beta$-catenin phosphorylation, which leads to $\beta$-catenin polyubiquitination and degradation.

The phosphorylation of $\beta$-catenin is essential for polyubiquitination mediated by the $\mathrm{E} 3$ ubiquitin ligase, $\mathrm{SCF}^{\beta \operatorname{TrCP}}$. $\mathrm{SCF}^{\beta T r C P}$ recognizes and binds the consensus sequence (D-pS-G-XX-pS) on substrates (43). GSK-3 $\beta$ phosphorylates Ser and Thr residues in the phosphorylation consensus sequence (S/T-XXX-pS/pT). Before GSK-3 $\beta$-mediated phosphorylation, the downstream Ser or Thr in the sequence (S/T-XXX-S/T) has to first be phosphorylated by a priming kinase. The priming kinase for GSK-3 $\beta$ is casein kinase 1 (CK1), which phosphorylates Ser45 in $\beta$-catenin. Following the CK1-mediated phosphorylation of $\beta$-catenin at Ser45, GSK-3 $\beta$ phosphorylates the Ser33, Ser37 and Thr41 residues in $\beta$-catenin $(44,45)$. Since the present study demonstrated that derivative \#5 increased both the phosphorylation of $\beta$-catenin at Ser33/Ser37/Thr41 (Fig. 5C and D) and the polyubiquitination of $\beta$-catenin (Fig. 5E), it was thus hypothesized that derivative \#5 would enhance GSK-3 $\beta$-mediated $\beta$-catenin phosphorylation. In addition, it was hypothesized that derivative \#5 may affect the priming phosphorylation (i.e., Ser45 of $\beta$-catenin) by $\mathrm{CK} 1$.

In order to improve the aqueous solubility of fullerene, various hydrophilic groups were added to the fullerene core. It has been reported that water-soluble fullerene derivatives exhibit unique and characteristic pharmacological effects, as mentioned in the Introduction section. In the present study, fullerene derivatives containing a pyrrolidinium or pyridinium moiety as the hydrophilic group were generated, and nine cationic fullerene derivatives were evaluated. It was previously found that derivatives \#1 and \#5 displayed HIV RT inhibitory activity (24,25). Moreover, derivative \#7 inhibited both HIV RT and HIV protease (24). Derivatives \#1 and \#5 also exerted influenza virus endonuclease (20) and HCV NS5B inhibitory activities (19), respectively. Derivatives \#1, \#3 and \#5 suppressed cancer cell proliferation $(21,23)$. Furthermore, it was disclosed that derivatives \#1 and \#5 dysregulated the AKT (21) and Wnt/ $\beta$-catenin (the present study) signaling pathways, respectively. Based on the aforementioned biological properties of the pyrrolidinium/pyridinium-type fullerene derivatives, these derivatives may be utilized as novel compounds for the treatment of various types of cancer.

The present study aimed to find the effective anticancer compounds for PEL and to disclose underlying the molecular mechanisms leading to their anticancer effects. To achieve this, nine fullerene derivatives were synthesized. The strength of the study lies in the novelty of compounds. The authors designed and synthesized these fullerene derivatives with a yield of 50-100 mg per compound. However, the present study had a research resource limitation; the authors could not unrestrictedly use derivative \#5. Thus, several western blotting experiments for quantitative analysis (Figs. 3A, 4A, 5B-E and S2) could not be repeated more than three times. However, these data were confirmed twice using western blot analysis using independent samples. Further studies to identify the simple and high-yielding synthetic approach for fullerene derivatives are currently underway.

In conclusion, the present study demonstrated that the pyridinium-type fullerene derivative \#5 (3-[5'-(ethoxycarbonyl) -1',5'-dihydro-2'H-[5,6]fullereno- $\mathrm{C}_{60}-\mathrm{I}_{\mathrm{h}}$-[1,9-c]pyrrol-2'-yl]-1methylpyridinium iodide) suppressed $\mathrm{Wnt} / \beta$-catenin signaling in PEL cells via $\beta$-catenin downregulation, which resulted in a decrease in PEL cell viability. These biological functions of derivative \#5 serve as an anti-proliferative effector in PEL cells. Therefore, KSHV-infected PEL cells may be more sensitive to the anti-proliferative effect of derivative \#5 than KSHV-uninfected cells, indicating that derivative \#5 may serve as an effective treatment for PEL and KSHV-associated cancers.

\section{Acknowledgements}

Not applicable.

\section{Funding}

The present study was supported in part by the JSPS Grant-in-Aid for Scientific Research (18K06642).

\section{Availability of data and materials}

The datasets used and/or analyzed during the current study are available from the corresponding author on reasonable request.

\section{Authors' contributions}

AK, MM, TW, YS, TO, TM and MF designed the experiments. AK performed the experiments and collected the data. AK and MM analyzed and interpreted the data. TY, SN, TA, TO and TM designed and synthesized the fullerene derivatives. AK drafted the manuscript, and TO and MF reviewed and edited the manuscript. TO and MF confirm the authenticity of all the raw data. All the authors have read and approved the final version of the manuscript.

\section{Ethics approval and consent to participate}

All experimental methods were performed in accordance with relevant guidelines and regulations. The animal protocol was approved by the committee on the Ethics of Animal Research of Kyoto Pharmaceutical University (Approval no. 18-039), and all experiments were performed in accordance with the National Institutes of Health Guide for Care and Use of Laboratory Animals.

\section{Patient consent for publication}

Not applicable. 


\section{Competing interests}

The authors declare that they have no competing interests.

\section{References}

1. Russo JJ, Bohenzky RA, Chien MC, Chen J, Yan M, Maddalena D, Parry JP, Peruzzi D, Edelman IS, Chang Y and Moore PS: Nucleotide sequence of the Kaposi sarcoma-associated herpesvirus (HHV8). Proc Natl Acad Sci USA 93: 14862-14867, 1996.

2. Nador RG, Cesarman E, Chadburn A, Dawson DB, Ansari MQ, Sald $\mathbf{J}$ and Knowles DM: Primary effusion lymphoma: A distinct clinicopathologic entity associated with the Kaposi's sarcoma-associated herpes virus. Blood 88: 645-656, 1996.

3. Chang Y, Cesarman E, Pessin MS, Lee F, Culpepper J, Knowles DM and Moore PS: Identification of herpesvirus-like DNA sequences in AIDS-associated Kaposi's sarcoma. Science 266: 1865-1869, 1994.

4. Watanabe T, Sugimoto A, Hosokawa K and Fujimuro M: Signal transduction pathways associated with KSHV-related tumors. In: Human Herpesviruses. Kawaguchi Y, Mori Y and Kimura H (eds). Springer, Berlin/Heidelberg, pp321-355, 2018.

5. Damania B and Cesarman E: Kaposi's sarcoma-associated herpesvirus. In: Fields Virology. 6th edition. Knipe DM and Howley PM (eds). Lippincott Williams \& Wilkins, pp2080-2128, 2013.

6. Fujimuro M, Wu FY, ApRhys C, Kajumbula H, Young DB Hayward GS and Hayward SD: A novel viral mechanism for dysregulation of beta-catenin in Kaposis sarcoma-associated herpesvirus latency. Nat Med 9: 300-306, 2003.

7. Fujimuro M and Hayward SD: The latency-associated nuclear antigen of Kaposi's sarcoma-associated herpesvirus manipulates the activity of glycogen synthase kinase-3beta. J Virol 77: 8019-8030, 2003.

8. Fujimuro M, Liu J, Zhu J, Yokosawa H and Hayward SD Regulation of the interaction between glycogen synthase kinase 3 and the Kaposi's sarcoma-associated herpesvirus latency-associated nuclear antigen. J Virol 79: 10429-10441, 2005.

9. Hayward SD, Liu J and Fujimuro M: Notch and Wnt signaling: Mimicry and manipulation by gamma herpesviruses. Sci STKE 2006: re4, 2006

10. Kroto HW, Heath JR, O'Brien SC, Curl RF and Smalley RE: $\mathrm{C}_{60}$ : Buckminsterfullerene. Nature 318: 162-163, 1985.

11. Zakharian TY, Seryshev A, Sitharaman B, Gilbert BE, Knight V and Wilson LJ: A fullerene-paclitaxel chemotherapeutic: Synthesis, characterization, and study of biological activity in tissue culture. J Am Chem Soc 127: 12508-12509, 2005.

12. Chaudhuri P, Paraskar A, Soni S, Mashelkar RA and Sengupta S: Fullerenol-cytotoxic conjugates for cancer chemotherapy. ACS Nano 3: 2505-2514, 2009.

13. Isobe $\mathrm{H}$, Nakanishi $\mathrm{W}$, Tomita $\mathrm{N}$, Jinno $\mathrm{S}$, Okayama $\mathrm{H}$ and Nakamura E: Nonviral gene delivery by tetraamino fullerene. Mol Pharm 3: 124-134, 2006.

14. Tokuyama H, Yamago S, Nakamura E, Shiraki T and Sugiura Y: Photoinduced biochemical activity of fullerene carboxylic acid. J Am Chem Soc 115: 7918-7919, 1993.

15. Okuda K, Mashino T and Hirobe M: Superoxide radical quenching and cytochrome c peroxidase-like activity of $\mathrm{C}_{60}$-dimalonic acid, $\mathrm{C}_{64}(\mathrm{COOH})_{4}$. Bioorg Med Chem Lett 6: 539-542, 1996.

16. Nishizawa C, Hashimoto N, Yokoo S, Funakoshi-Tago M, Kasahara T, Takahashi K, Nakamura S and Mashino T: Pyrrolidinium-type fullerene derivative-induced apoptosis by the generation of reactive oxygen species in HL-60 cells. Free Radical Res 43: 1240-1247, 2009.

17. Mashino T, Nishikawa D, Takahashi K, Usui N, Yamori T, Seki M, Endo T and Mochizuki M: Antibacterial and antiproliferative activity of cationic fullerene derivatives. Bioorg Med Chem Lett 13: 4395-4397, 2003.

18. Friedman SH, DeCamp DL, Sijbesma RP, Srdanov G, Wudl F and Kenyon GL: Inhibition of the HIV-1 protease by fullerene derivatives: Model building studies and experimental verification. J Am Chem Soc 115: 6506-6509, 1993.
19. Mashino T, Shimotohno K, Ikegami N, Nishikawa D, Okuda K, Takahashi K, Nakamura S and Mochizuki M: Human immunodeficiency virus-reverse transcriptase inhibition and hepatitis $\mathrm{C}$ virus RNA-dependent RNA polymerase inhibition activities of fullerene derivative. Bioorg Med Chem Lett 15: 1107-1109, 2005.

20. Shoji M, Takahashi E, Hatakeyama D, Iwai Y, Morita Y, Shirayama R, Echigo N, Kido H, Nakamura S, Mashino T, et al. Anti-influenza activity of $\mathrm{C}_{60}$ fullerene derivatives. PLoS One 8: e66337, 2013

21. Watanabe T, Nakamura S, Ono T, Ui S, Yagi S, Kagawa H, Watanabe H, Ohe T, Mashino T and Fujimuro M: Pyrrolidinium fullerene induces apoptosis by activation of procaspase-9 via suppression of Akt in primary effusion lymphoma. Biochem Biophys Res Commun 451: 93-100, 2014.

22. Cardone MH, Roy N, Stennicke HR, Salvasen GS, Franke TF, Stanbridge E, Frisch S and Reed JC: Regulation of cell death protease caspase-9 by phosphorylation. Science 282: 1318-1321, 1998.

23. Yasuno T, Ohe T, Ikeda $\mathrm{H}$, Takahashi K, Nakamura $\mathrm{S}$ and Mashino T: Synthesis and antitumor activity of novel pyridinium fullerene derivatives. Int J Nanomedicine 14: 6325-6337, 2019.

24. Yasuno $\mathrm{T}$, Ohe $\mathrm{T}$, Kataoka $\mathrm{H}$, Hashimoto $\mathrm{K}$, Ishikawa $\mathrm{Y}$, Furukawa K, Tateishi Y, Kobayashi T, Takahashi K, Nakamura S and Mashino T: Fullerene derivatives as dual inhibitors of HIV-1 reverse transcriptase and protease. Bioorg Med Chem Lett 31: 127675, 2021.

25. Yasuno T, Ohe T, Takahashi K, Nakamura S and Mashino T: The human immunodeficiency virus-reverse transcriptase inhibition activity of novel pyridine/pyridinium-type fullerene derivatives. Bioorg Med Chem Lett 25: 3226-3229, 2015.

26. Shigemi Z, Furukawa Y, Hosokawa K, Minami S, Matsuhiro J, Nakata S, Watanabe T, Kagawa H, Nakagawa K, Takeda H and Fujimuro M: Diallyl trisulfide induces apoptosis by suppressing $\mathrm{NF}-\kappa \mathrm{B}$ signaling through destabilization of TRAF6 in primary effusion lymphoma. Int J Oncol 48: 293-304, 2016

27. Fujimuro M, Sawada $\mathrm{H}$ and Yokosawa $\mathrm{H}$ : Production and characterization of monoclonal antibodies specific to multi-ubiquitin chains of polyubiquitinated proteins. FEBS Lett 349: 172-180, 1994.

28. Livak KJ and Schmittgen TD: Analysis of relative gene expression data using real-time quantitative PCR and the 2(-Delta Delta C(T)) method. Methods 25: 402-408. 2001

29. Chen $\mathrm{C}$ and Okayama H: High-efficiency transformation of mammalian cells by plasmid DNA. Mol Cell Biol 7: 2745-2752, 1987.

30. Takahashi-Makise N, Suzu S, Hiyoshi M, Ohsugi T, Katano H, Umezawa $\mathrm{K}$ and Okada S: Biscoclaurine alkaloid cepharanthine inhibits the growth of primary effusion lymphoma in vitro and in vivo and induces apoptosis via suppression of the NF-kappaB pathway. Int J Cancer 125: 1464-1472, 2009.

31. Kim YJ, Kim Y, Kumar A, Kim CW, Toth Z, Cho NH and Lee HR: Kaposi's sarcoma-associated herpesvirus latency-associated nuclear antigen dysregulates expression of MCL-1 by targeting FBW7. PLoS Pathog 17: e1009179, 2021.

32. Saji C, Higashi C, Niinaka Y, Yamada K, Noguchi $K$ and Fujimuro M: Proteasome inhibitors induce apoptosis and reduce viral replication in primary effusion lymphoma cells. Biochem Biophys Res Commun 415: 573-578, 2011.

33. Higashi C, Saji C, Yamada K, Kagawa H, Ohga R, Taira T and Fujimuro M: The effects of heat shock protein 90 inhibitors on apoptosis and viral replication in primary effusion lymphoma cells. Biol Pharm Bull 35: 725-730, 2012.

34. Ishiura Y, Ishimaru H, Watanabe T and Fujimuro M: Sulforaphane exhibits cytotoxic effects against primary effusion lymphoma cells by suppressing p38MAPK and AKT phosphorylation. Bio Pharm Biol 42: 2109-2112, 2019.

35. Moriguchi M, Watanabe T, Kadota A and Fujimuro M: Capsaicin induces apoptosis in KSHV-pisitive primary effusion lymphoma by suppressing ERK and p38 MAPK signaling and IL-6 expression. Front Oncol 9: 83, 2019

36. Wakao K, Watanabe T, Takadama T, Ui S, Shigemi Z, Kagawa H, Higashi C, Ohga R, Taira T and Fujimuro M: Sangivamycin induces apoptosis by suppressing Erk signaling in primary effusion lymphoma cells. Biochem Biophys Res Commun 444: $135-140,2014$.

37. Willert $\mathrm{K}$ and Jones $\mathrm{KA}$ : Wnt signaling: Is the party in the nucleus? Genes Dev 20: 1394-1404, 2006.

38. Kimelman D and Xu W: beta-catenin destruction complex: Insights and questions from a structural perspective. Oncogene 25: 7482-7491, 2006 
39. Albrecht LV, Tejeda-Muñoz N and De Robertis EM: Cell biology of canonical Wnt signaling. Annu Rev Cell Dev Biol 37: 369-389, 2021.

40. Hoppler S and Kavanagh CL: Wnt signalling: variety at the core. J Cell Sci 120: 385-393, 2007.

41. Segditsas S and Tomlinson I: Colorectal cancer and genetic alterations in the Wnt pathway. Oncogene 25: 7531-7537, 2006.

42. Clements WM, Wang J, Sarnaik A, Kim OJ, MacDonald J, Fenoglio-Preiser C, Groden J and Lowy AM: beta-Catenin mutation is a frequent cause of Wnt pathway activation in gastric cancer. Cancer Res 62: 3503-3506, 2002.

43. Nakayama KI and Nakayama K: Ubiquitin ligases: Cell-cycle control and cancer. Nat Rev Cancer 6: 369-381, 2006.
44. Liu C, Li Y, Semenov M, Han C, Baeg GH, Tan Y, Zhang Z, Lin $\mathrm{X}$ and $\mathrm{He} \mathrm{X}$ : Control of beta-catenin phosphorylation/degradation by a dual-kinase mechanism. Cell 108: 837-847, 2002.

45. Amit S, Hatzubai A, Birman Y, Andersen JS, Ben-Shushan E, Mann M, Ben-Neriah Y and Alkalay I: Axin-mediated CKI phosphorylation of $\beta$-catenin at Ser 45: A molecular switch for the Wnt pathway. Genes Dev 16: 1066-1076, 2002.

This work is licensed under a Creative Commons Attribution-NonCommercial-NoDerivatives 4.0 International (CC BY-NC-ND 4.0) License. 